Dr. Abosaif, Mahmoud Sayed Ali

Volume (1) No. (4) 2018

\title{
دور جودة حياة العمل في العلاقة بين رأس المال النفسي ومستوى الالتزام التنظيمي لدى أعضاء هيئة التدريس بكلية التربية في جامعة الطائف بالمملكة العربية السعودية
}

/ محمود سيد علي أبو سيف 
دور جودة حياة العمل في العلاقة بين رأس المال النفسي ومستوى الالتزام التنظيمي لدى أعضاء هيئة التدريس بكلية التربية في جامعة الطائف بالمملكة العربية السعودية

$$
\text { د. محمودسيد علي أبوسيف }
$$

أستاذمساعد الإدارة التعليمية، البرنامج الانتقلي، السنة الأولى المشتركة، جامعة الملك سعود،

\section{Dr.mabosaif@yahoo.com}

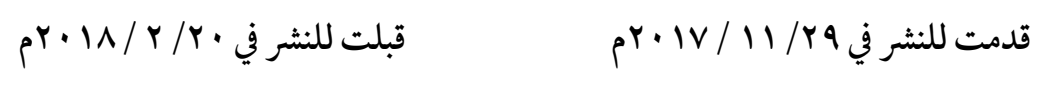

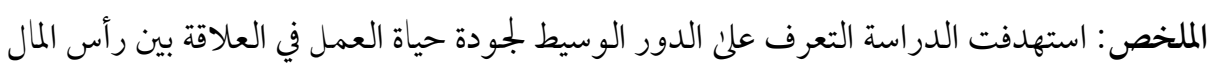

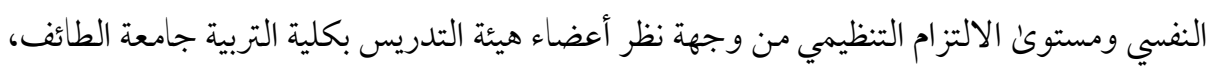

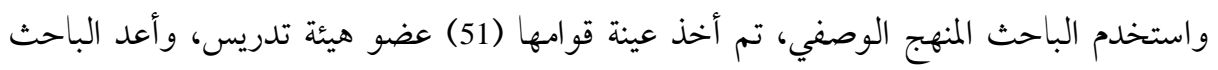

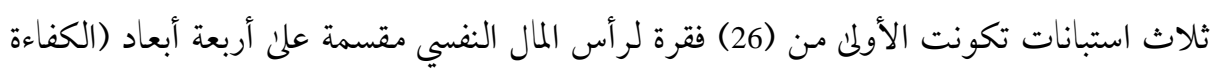

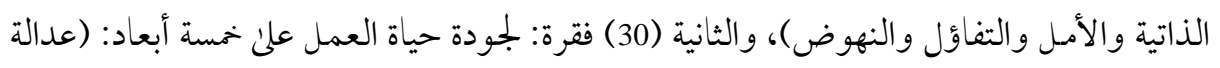

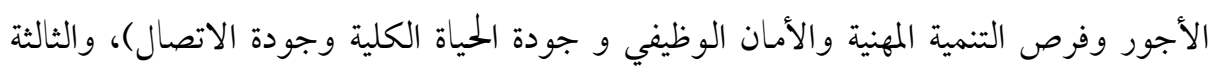

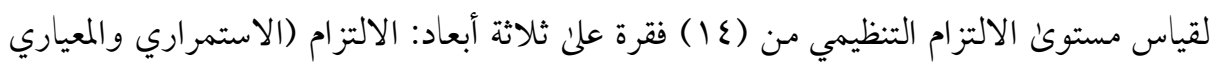
والعاطفي). وقد تم استخدام برنامج (SPSS) ، وتم تحليل الوساطة باستخدام العمليات الكلية (Macro process)

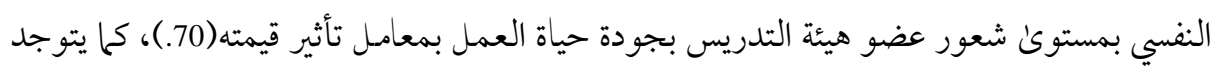

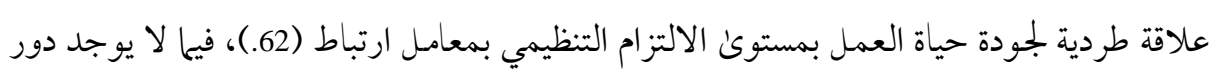

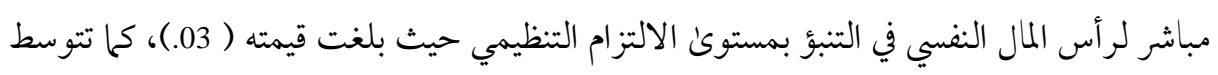

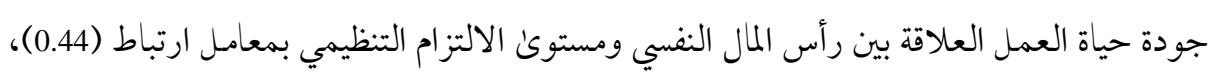

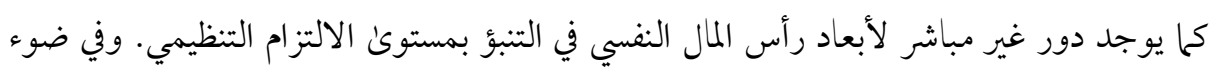

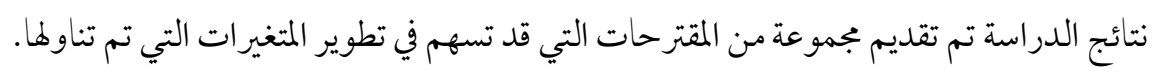

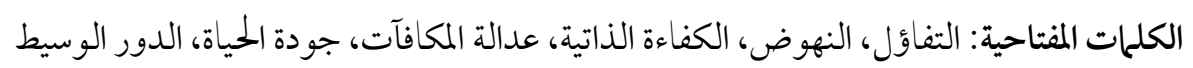




\title{
The role of quality of work life in the relationship between psychological capital and organizational commitment among faculty members at the Faculty of Education, Taif University
}

\author{
Abosaif, Mahmoud Sayed Ali \\ Asistant professor of Educational Adminstration, transitional program, Common First \\ Year, King Saud University Dr.mabosaif@yahoo.com \\ Presented in 29 November 2017 Accepted in 20 Feb 2018
}

\begin{abstract}
This study aimed at investigating whether psychological capital (consisting of hope, resilience, optimism, and efficacy) has a relationship with organizational commitment, and to further examine whether quality of work life can serve as a mediator between psychological capital and organizational commitment in the Faculty of Education, Taif University. Descriptive approach was used primarily as the methodology of this study to test mediation model with a sample of (51) faculty members. Three questionnaires were prepared to measure: psychological capital composed of (26) items in four dimensions (self-efficacy, hope, optimism and resilience), quality of work life composed of (30) items in five dimensions: (salaries justice, professional development opportunities, security, general life and communication) and commitment composed of (14) items in three dimensions: (continuous and normative and emotional) commitment. The SPSS program was used by adding the Macro analysis process of Hayes (2013). The Results reveal that psychological capital has a direct role in predicting the faculty member's sense of quality of work life with influence factor of (.70). There is also a relation between the quality of work life and organizational commitment with influence factor of (.62), while there is no direct role of psychological capital in predicting the level of organizational commitment with factor (.03). The quality of work life also mediates the relationship between psychological capital and the level of organizational commitment with influence factor (0.44). The implications of these findings conclude in the article.
\end{abstract}

Keywords: Mediation Role - Optimism - Self Efficacy- Resilience- Equitable salaries -quality of life 


$$
\text { / محمود سيد علي أبو سيف }
$$

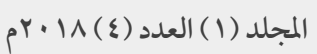

\section{The Article Summary}

\section{Introduction}

The current study aimed at identifying the relationship between psychological capital and organizational commitment, as well as the intermediate role of the quality of work life in the relationship between Psychological capital and organizational commitment among faculty members at the Faculty of Education, Taif University.

Several studies have shown there are some challenges face faculty members in Saudi universities such as Al-Yousef (1433), which dealt with the most important problems affecting the quality of their work life, like social problems: the scarcity of an association on the rights of faculty members and weak incentives for creative members, academic problems such as the multiplicity of tasks of the faculty member between administrative and academic, the weakness in the academic guidance of the students doubles the efforts of the faculty member, and administrative problems such as the slow process of administrative formalities, and the scarcity of the amendment of the salary scale of faculty members .

There are various studies dealt with the variables of the study such as Sherbini (2013), which dealt with the quality of work life as a mediator in the relationship between organizational excellence, organizational commitment and the study of Abu Lifa (2016), which dealt with the role of positive psychological capital in the relationship between the quality of life and career And the study of the reality of Saudi Almarshad study (2015), which dealt with the relationship between the quality of work life and the organizational commitment with the role of mediators of other variables, but the current study was not addressed in terms of variables or field of application.

\section{Problem of the study}

Based on what presented in the introduction, the study tries to answer the following main question:

What is the role of quality of work life in the relationship between psychological capital and their organizational commitment from the points of view of faculty members of the Faculty of Education at Taif University? 


\section{It is divided into the following sub-questions:}

- What is the level of psychological capital and its four dimensions among faculty members at the Faculty of Education at Taif University?

- What is the level of the quality of work life and its five dimensions among faculty members at the Faculty of Education, Taif University?

- What is the level of organizational commitment in its three dimensions among the faculty members of the Faculty of Education at Taif University?

- To what extent does psychological capital (and its four dimensions) correlate with organizational commitment?

- To what extent does psychological capital (and its four dimensions) correlate with the quality of work life?

- To what extent does quality of work life (and its five dimensions) correlate with organizational commitment?

\section{Hypotheses of the Study}

The main hypothesis of the study can be formulated as follows: "The quality of work life does not affect the relationship between psychological capital and organizational commitment among faculty members of the Faculty of Education, Taif University, track (c) next:

- There is a significant correlation between psychological capital and quality of work life and its dimensions (Track A)

- There is a significant correlation between quality of work life and its dimensions with organizational commitment. (Track B)

- There is a significant correlation between psychological capital and its dimensions with organizational commitment. (Track C)

\section{Objectives of the study:}

The main objective of the current study is to identify the intermediate role of the quality of work life in the relationship between Psychological capital and organizational commitment among faculty members at the Faculty of Education, Taif University. Furthermore divided into next: 
- Identifying the level of psychological capital and its components among faculty members at the Faculty of Education at Taif University

- Identifying the level of quality of work life and its dimensions.

- Measuring the level of organizational commitment and its dimensions.

- Identifying the relationship between the psychological capitals prevailing among faculty members with the level of their organizational commitment?

- Identifying the relationship between psychological capitals of faculty members with the quality of work life?

- Identifying the relationship between qualities of work life among faculty members with their organizational commitment?

\section{Importance of the study:}

At the scientific level, the study is in addition to the literature. The researcher did not find any study related to the impact of psychological capital on the relation between organizational commitment and quality of work life among faculty members in the universities of Saudi Arabia.

Methods of the study: the study used the descriptive approach. To collect data questionnaires were used on Likert scale ( $1=$ strongly disagree, $5=$ strongly agree) and included a set of questions related to the three variables of study as follows:

a. measurements

- Psychological capital: psychological capital was measured by scale of Positive Psy Cap (Luthans et al., 2007) which consists of four dimensions namely hope, optimism, self-efficacy and resilience. It is based also on Scheier and Carver's (1985) scale of hope, for optimism Parker's (1998) (6 items), for Self-efficacy (7 items), for resilience Wagnild and Young's (1993) (7 items), with total number (26 items), with increase of two items from Luthans scale of psychological capital.

- Quality of Work Life: The researcher created the quality of work life scale based on Walton scale and Sirgy et al. (2001), the six-dimensional. Easton \& Van Laar (2013) and Lewis et al. (2001). Five dimensions were measured, namely fair wages or incentives (6 items), career development opportunities (7 items), job security (6 items), formal and informal communication (5 
items), and finally quality of general life (6 items) with a total of 30 items for the scale.

- Organizational commitment scale: based on the literature and mainly on Meyer and Allen (1991) and Meyer, Allen and Smith (1993) with a total of 14 items for the scale.

b. Sample: The sample of the study consisted of faculty members at faculty of education at Taif University. The sample consisted of 51 faculty members

c. Statistical analysis: the study depended on Model 4 PROCESS MACRO to test mediation and the indirect effect of $95 \%$ bias-corrected (BC) Confidence intervals (CI) 5000 (Hayes, 2013; Preacher \& Hayes, 2004).

\section{Results of the study}

Results can be clarified in the following points:

- The level of psychological capital among the faculty members at the Faculty of Education at Taif University was high (4.03).

- The overall level of quality of work life at the Faculty of Education at Taif University was average (3.38).

- The level of organizational commitment at the faculty of education at Taif University was average. The mean was 3.54 .

- Acceptance of the first hypothesis that there is a relationship between psychological capital and quality of work life at a level of significance less than .05

- Accepting the second hypothesis that there is a relationship between the quality of work life and organizational commitment.

- The third hypothesis was rejected. The relationship between psychological capital and the level of organizational commitment wasn't significant, where the value of the direct effect of psychological capital at organizational commitment was (.03) at a level of significance (.82)

- The fourth hypothesis was rejected. Quality of work life mediated of the relationship between psychological capital and organizational commitment, with indirect impact $(0.44)$

- All dimensions of quality of work life mediated the relationship between psychological capital and organizational commitment among faculty members at the Faculty of Education Taif University: 
○ The indirect effect of wages and fair incentives was (.4637). The indirect effect of professional development reached (.4818). The indirect effect of the quality of general life (.3973), the quality of internal and external communication also played the role of mediator with effect level (.2916).

- The significance of the intermediate role of the quality of work life on the relation between dimensions of psychological capital and organizational commitment was:

- On the self-efficacy relationship with the level of organizational commitment (0.42) significance level of (P) was 0.01

○ On the relationship of optimism to the organizational commitment (.39), and the significance level of $(\mathrm{P})$ was (.005)

- On the relationship of the level of hope to the level of the organizational commitment (.38) significance level of (P) was(.002)

○ On the relationship of the improvement of the level of organizational commitment (0.43) significance level of (P) was (.03) 
يعد التعليم العالي منظومة ترتبط بعدة عناصر منها أعضاء هيئة التدريس والطلبة والمناهج وإدارات الجامعات، وتتداخل كل هذه العناصر معاً لتؤثر علن نوعية وجودة التعليم العلي، وبقدر توافر الجودة في كل هذه العناصر، تتحقق جودة التعليم العلي. وتعد الموارد البشرية التي تمتلكها الجامعات المصدر الأهم للتنافسية، وبالتالي اهتمت الأدبيات بدراسة العوامل التي تعيق، أو تدعم مستوى الأداء عنده، ومن بين هذه المفاهيم رأس المال النفسي، والذي يشكل بجموعه لديهم (مـا يمتلكه الفرد من قدرة علن النهوض ومستون كفاءته الذاتية ومستوئ الأمل والمرونة) بجموع رأس لئ المال النفسي لدئ المنظمة (Luthans، 2007) ، فكلما زاد اهتحام مستوئ رأس الملال النفيي لدئ الموظفين زاد مستوئ الأداء لديهم كما جاء بدراسة (2013) Erkuş\& Findikli. وبها أن العنصر البشري أصبح المورد الأكثر قيمة في موارد المنظمة، فإن بيئة العمل المضطربة والمتوترة (مثل تشديد الضغط عليه، أو البيروقر اطية أو ضعف الأجور ... وغيرها) أدئ إلى لئ ظهور الاهتمام بمصطلح جودة حياة العمل، وهو مفهوم شامل يتكون من الصحة البدنية والنفسية، والأوضاع الاقتصادية، والمعتقدات والتفاعل الشخصي مع البيئة (Khorsandi et al., 2010)، وينعكس اهتحام الجحامعات بشؤون أعضاء هيئة التدريس سواء علن المستوىن النفسي وعلن مستوىن جودة حياة العمل على مجموعة من العوامل الأخرى لديهم مثل مستوى الرضا الوظيفي والمواطنة التنظيمية والالتزام التنظيمي كما أثبتهه العديد من الدراسات مثل دراسة (2014) Gokhan\& Azize ودراسة .Jung \& Yoon (2015) و انطلاقا مما سبق جاءت الدراسة الحالية للتركيز علن ثلاثة متغيرات خاصة بالعنصر البشري المهم لدى الجمامعات وهم أعضاء هيئة التدريس من خلال التعرف علئ مستون العلاقة، والتأثير بين رأس المال النفسي وجودة حياة العمل علن مستون الالتزام التنظيمي، كذلك التعرف علن الدور الوسيط لجودة حياة العمل في العلاقة بين رأس المال النفسي ومستوئ الالتزام التنظيمي لدئ أعضاء هيئة التدريس بكلية التربية جامعة الطائف. 


\section{مشكلة الدراسة}

أظهرت العديد من الدراسات وجود بعض التحديات الخاصة بأعضاء هيئة التدريس في الجامعات السعودية مثل دراسة اليوسف (1433) التي تناولت أهم المشكلات التي تؤثر علن جودة حياة العمل لديهم مثل المشكلات الاجتماعية والمتمثلة في ندرة وجود جمعية تعنى بحقوق أعضاء هيئة التدريس، وضعف حوافز للمبدعين من أعضاء هيئة التدريس، والمشـكلات الأكاديميـة مثل تعدد

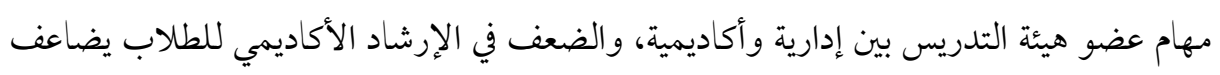
من جهود عضو هيئة التدريس، و المشكلات الإدارية مثل بطء سير المعاملات الرسمية الإدارية، وندرة تعديل سلم رواتب أعضاء هيئة التدريس.

كما تعددت الدراسات التي تناولت العلاقة بين متغيرات الدراسة مثل دراسة الشربيني (2013) التي تناولت جودة حياة العمل كوسيط في العلاقة بين التميز التنظيمي، والالتزام التنظيمي، ودراسة أبو ليفة (2016) التي تناولت دور رأس المال النفسي الإيجابي في العلاقة بين جودة الحياة الوظيفية والاستغراق الوظيفي، ومن بين الدراسات للواقع السعودي دراسة Almarshad (2015) التي تناولت العلاقة بين جودة حياة العمل والالتزام التنظيمي مع الدور الوسيط لمتغيرين آخرين، إلا أن موضوع الدراسة الحالية حسب الحصر الذي قام به الباحث لم يتم التطرق إليه من حيث المتغيرات

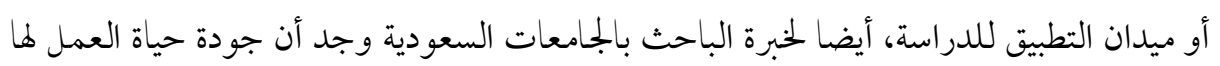

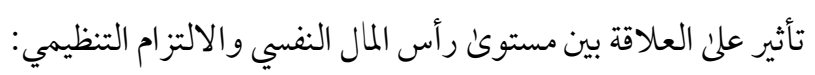
ويناء علن ما تم عرضه تحاول الدراسة الإجابة على السؤال الرئيس التالي: ما أثر جودة حياة العمل في العلاقة بين رأس المال النفسي السائد لدى أعضاء هيئة التدريس بكلية التربية بجامعة الطائف ومستوى التزامهم التنظيمي من وجهة نظرهم؟ 


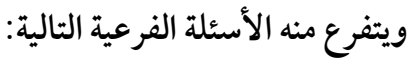

1- ما مستون رأس المال النفسي وأبعاده الأربعة لدئ أعضاء هيئة التدريس بكلية التربية

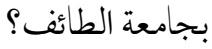

ץ- مـا مستوىن جودة حياة العمل وأبعاده الخمسة لدئ أعضاء هيئة التدريس بكلية التربية

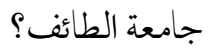

r- مـا مستوئ الالتزام التنظيمي وأبعاده الثلاثة لدنى أعضاء هيئة التدريس بكلية التربية بجامعة

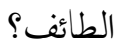

ع- مـاعلاقة رأس المال النفسي (و أبعاده الأربعة) لدئ أعضاء هيئة التدريس بمستوين التزامهم

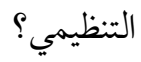

0- مـا علاقة رأس المال النفسي (وأبعاده الأربعة) التدريس لدن أعضاء هيئة بمستوى جودة

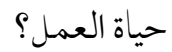

1 - ما علاقة جودة حياة العمل (وأبعاده الخمسة) بمستوئ الالتزام التنظيمي لدئ أعضاء هيئة

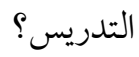

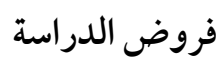

من خلال عرض الدراسات السابقة التي سيتم عرضها لاحقا يمكن صياغة الفرض الرئيس

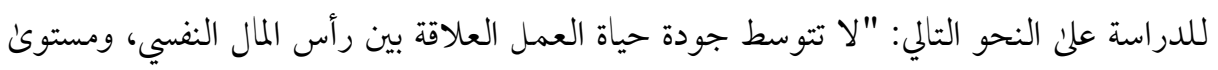

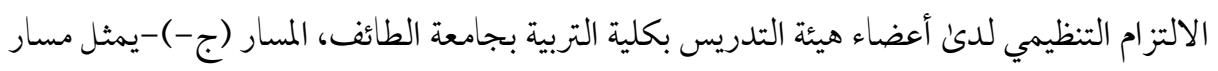

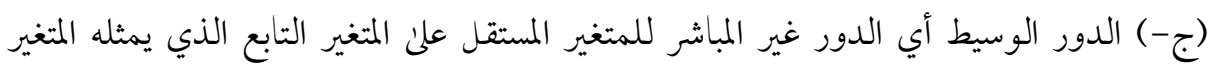
الوسيط، ويتفرع من الفروض التالية:

1 - يوجد ارتباط طردي معنوي بين رأس المال النفسي السائد بجودة حياة العمل، وأبعادها

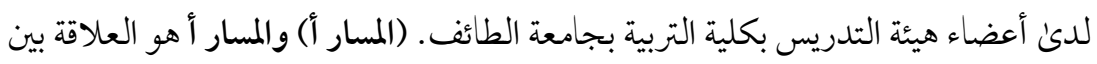

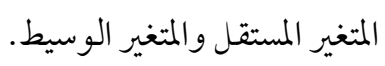


r- - يوجد ارتباط طردي معنوي بين مستون جودة حياة العمل، وأبعاده بمستوى الالتزام

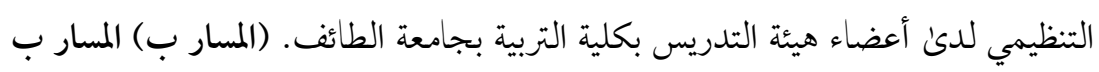

$$
\text { هو العلاقة بين المتغير الوسيط والمتغير التابع. }
$$

r- يوجد ارتباط طردي معنوي بين مستوى رأس المال النفسي، وأبعاده مع مستوئ الالتزام

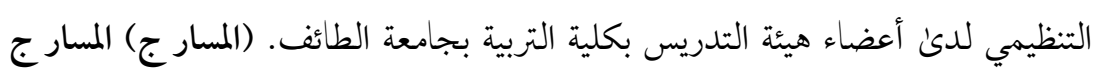

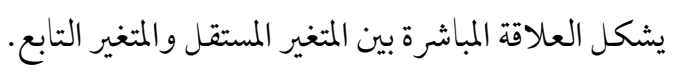

أهداف الدراسة

يتبلور الهدف الرئيس للدراسة الحالية في قياس الدور الوسيط لمستون جودة حياة العمل في العلاقة بين رأس المال النفسي والالتزام التنظيمي من وجهة نظر أعضاء هيئة التدريس بكلية التربية بجامعة الطائف، ويتفرع منه الأهداف الفرعية التالية: ا - التعرف علن مستون رأس المال النفسي ومكوناته لدن أعضاء هيئة التدريس بكلية التربية بجامعة الطائف.

r- التعرف علن مستوى شعور أعضاء هيئة التدريس بمستوك جودة حياة العمل وأبعادها.

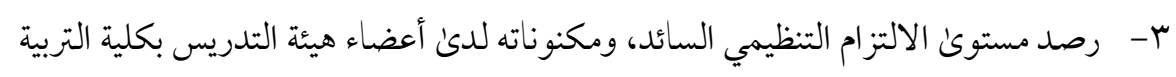
بجامعة الطائف. ع- - رصد العلاقة بين رأس المال النفي السائد لدئ أعضاء هيئة التدريس علن مستون التزامهم التنظيمي؟ رمدا؟ ه- التعرف علن العلاقة بين رأس المال النفسي لدن أعضاء هيئة التدريس علن مستوىن جودة حياة العمل؟

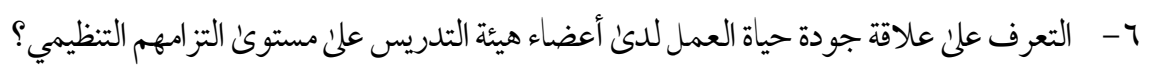

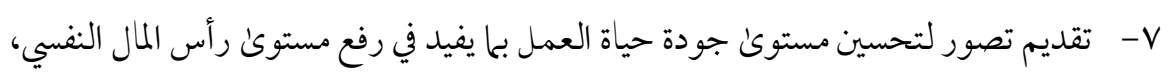
وينعكس علن مستوئ الالتزام التنظيمي لدئ أعضاء هيئة التدريس. 


\section{أهمية الدراسة}

علن المستوئ النظري تعد الدراسة إضافة للأدبيات العلمية، وقام الباحث بحصر الأبحاث الموجودة بقواعد المعلومات العربية، ولم يجد أي دراسة تتعلق بأثر رأس المال النفسي على مستوىن الالتزام التنظيمي في وجود جودة حياة العمل كمتغير وسيط لدى أعضاء هيئة التدريس في جامعات المملكة العربية السعودية؛ لذلك يهظى البحث بأهمية علن مستوى الجامعات التي تبحث عن النجاح والتميز في ظل المنافسة بين الجامعات محليا، وإقليميا وعالميا. أمـا على المستون التطبيقي، لعل هذه الدراسة تفيد المسؤولين في جامعة الطائف في التعرف علن مستوىن جودة حياة العمل، ومستونى الالتزام التنظيمي، ومستوى رأس المال النفسي السائدة لديهم، والتعرف على علاقة وتأثير هذه المتغيرات ببعضها؛ مما قد يفيد الجامعة، وبالأخص كلية التربية في تنمية المستونى الأكاديمي والمهني لديهr.

\section{حدود الدراسة}

طبقت الدراسة الميدانية في إطار زمني ومكاني وموضوعي يمكن تناوله علن النحو التالي: ا- الحدود المكانية: طبقت الدراسة في كلية التربية بجامعة الطائف، بمحافظة الطائف في

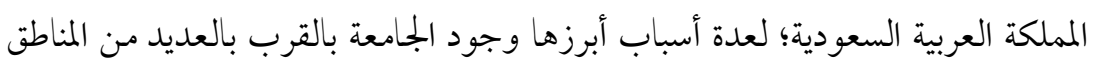

$$
\text { السعودية فهي تعد ممثلة بشكل جيد ويمكن تعميم النتائج المتحصل علن باقي الجامعات. }
$$

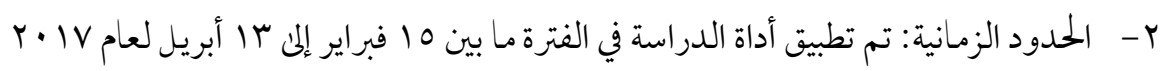
خلال الفصل الدراسي الثاني، وهي الفترة التي استهدفها الباحث بعد قضاء فترة مناسبة من أعضاء هيئة التدريس بالعمل لكي يتسنى رصد مستوى متغيرات الدراسة وأثرها بشكل دقيق. بـ- الحدود البشرية: تم تطبيق الدراسة علن أعضاء هيئة التدريس بكلية التربية بجامعة الطائف. 
ع - الحدود الموضوعية: اقتصر البحث علن رصد الدور الوسيط لجودة حياة العمل في العلاقة بين رأس المال النفسي والالتزام التنظيمي، وذلك في حدود التناول المفاهيمي لمفهوم المتغيرات، وأبعادها و إعداد أدوات الدراسة، وتحليلها لتلك المتغيرات.

\section{منهج الدراسة}

اعتمدت الدراسة علن المنهج الوصفي، حيث إنه يمثل أنسب المناهج للتعبير عن الظاهرة الاجتماعية المراد دراستها، والذي من خلاله استطاع الباحث التعبير عن مشكلة الدراسة كميا وكيفيا والوصول لاستناجات، وتوصيات يمكن تعميمها علن مجتمعات مشابهة لمجتمع الدراسة، وذلك بمعرفة وجهة نظر أعضاء هيئة التدريس بكلية التربية جامعة الطائف في مستوى متغيرات الدراسة، ودور جودة حياة العمل في العلاقة بين رأس المال النفسي ومستوئ الالتزام التنظيمي. مصطلحات الدراسة تتمركز مصطلحات الدراسة حول بعض المفاهيم علن النحو التالي: جودة حياة العمل Quality of work life: عرفها قاموس Business Dictionary علن أنها " المدئ الذي من خلاله يستطيع الموظف تحسين حياته الشخصية من خلال خبرات بيئة العمل" فيما لخص Walton (1973) مفهومها أنها رد فعل الموظفين علن العمل، خصوصا النتيجة الأساسية فيما يتعلق بالرضا الوظيفي والصحة النفسية. ووفقا لهذا التعريف، تؤكد جودة حياة العمل على النتائج الشخصية وخبرات العمل، وكيفية تحسين العمل من أجل تلبية الاحتياجات الشخصية. ويعرفها البحث الحلاي إجرائيا علن أنها بجموعة الظروف التي تهيء لرأس المال البشري الموجود بالمنظمة العمل والانتاجية في جو من الثبات المتوازن في طريقة إدارة الجامعة، مع مواكبة للتغيرات السريعة من خلال تنمية مهنية مناسبة لعضو هيئة التدريس، وتحسين الأوضاع المالية بما يتناسب مع الأعباء الأكاديمية والإدارية التي يقوم بها، إضافة لشعور المنسوبين بأنهم بمشاركة عاطفية من الإدارة لقضاياهم المهنية والشخصية، وشعوره بالملكية للمنظمة عند الحميث عنها. 


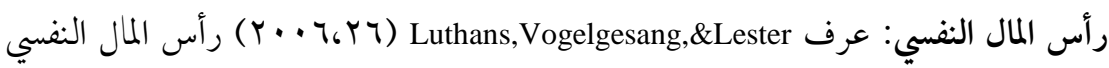
على أنه :"حالة التطور النفسي الإيجابية للأفراد والذي يتميز بأربع خصائص: امتلاك الثقة لتقديم الجهود المتفردة للنجاح في إنجاز المهام، وتوفر العزو الإيجابي لإمكانية النجاح الفوري والمستقبلي، والمثابرة تجاه تحقيق الأهداف من خلال المرونة في توجيه مسارات الأهداف، والقدرة علئ الاستفاقة

$$
\text { عند الاخفاق وحدوث المشكلات". }
$$

يعرفه البحث إجرائيا علن أنه بجموع ما يمتلكه عضو هيئة التدريس من سمات وسلوكيات ومعارف نفسية إيجابية تؤهله للعمل بشكل مميز، وامتلاكه لأبعاد التفكير الإبداعي في العمل خاصة المرونة والأصالة والحساسية للمشكلات، وتوفر الدافعية والطاقة التي تؤهله لبناء الصحة النفسية التنظيمية.

الالتزام التظيمي: يعرفها قاموس Business dictionary علن أنها:" قوة مشاعر المسئولية التي يكنها الموظف تجاه رسالة منظمته". فيها عرفها (Wright \& Kehoe 2007, 15) على أنها:"التقارب النفسي الذي يبنيه الموظف مع منظمته". يعرفه البحث إجر ائيا علن أنه سلوك يعبر عن ولاء الفرد وتماثله مع هوية جامعته وانتحهه ها، ويتنج عن اقتناع تام من قبله برسالة، وأهداف وقيم الجامعة يمكن أن يكون هذا السلوك ملموسا من خلال الأداء المتقن وتجاوز الساعات المقررة بالعمل، أو غير ملموس من خلال سعادته وفخره بوظيفته.

المتغير الوسيط: عرفه Undated) Butler ) بأنه :" المتغير الذي يحدد كيفية وسبب حدوث تأثير أو علاقة، فهو يوضح العملية النفسية التي تحدث أثناء بناء العلاقة الارتباطية أو الأثر". يعرفها الباحث إجرائيا علن أنه المتغير صاحب الأثر غير المباشر في مستوني التأثير المباشر أو العلاقة بين المتغير المستقل والمغير التابع، كما يمكن وصفه بأنه المفسر للعلاقة بين المتغيرين. ويتم حسابه من خلال طرح درجة التأثير المباشر من درجة التأثير الكلي لمتغير مستقل على متغير تابع. 
الدراسات السابقة: تم تقسيمها إلى ثلاثة أقسام: الأولى تتناول العلاقة والتأثير لرأس المال

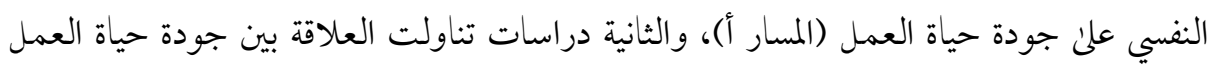
والالتزام التنظيمي (المسار ب)، والثالثة دراسات تناولت العلاقة بين رأس المال النفسي والالتزام

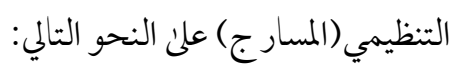
الدراسات التي تناولت العلاقة بين رأس المال النفسي وجودة حياة العمل وأبعاده: توصلت دراسة Mortazavi; Yazdi \& Amin (2012) التي طبقت علن عينة من 200 ممرضة

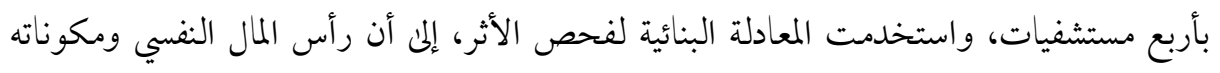

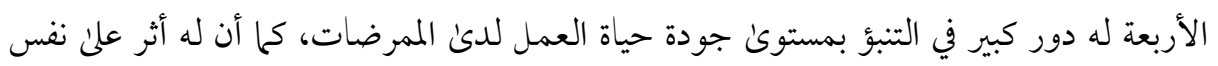

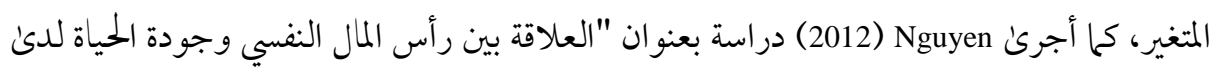

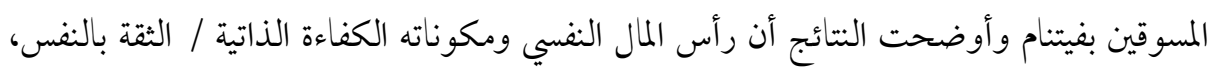

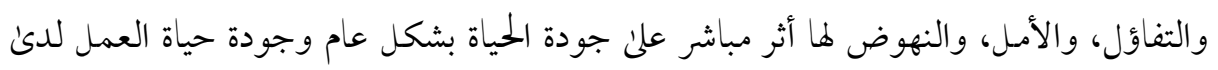

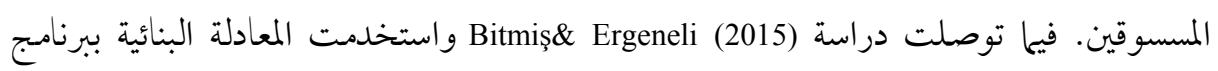
AMOS لوجود علاقة عكسية بين رأس المال النفسي، وضعف الأمان الوظيفي ( أحد أبعاد جودة حياة العمل) كما استهدفت دراسة 2016)Shabn, Parivash \& Nader) التعرف علئ العلاقة بين رأس المال النفيي، وجودة حياة العمل لدئ أعضاء هيئة التدريس في جامعة آزاد الإسلامية، وتم تطبيق الأداة

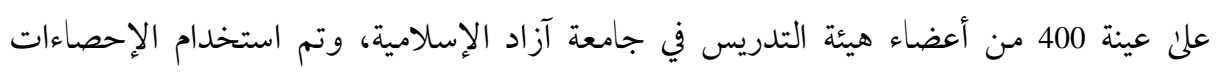

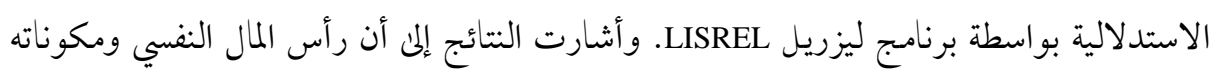

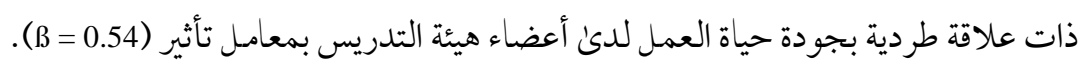
علنم مستوئ الأبعاد الفرعية تبين بجموعة من الدراسات وجود علاقة بلئ بين أبعاد رأس المال

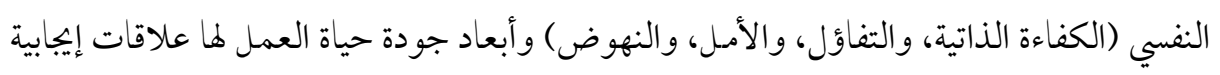

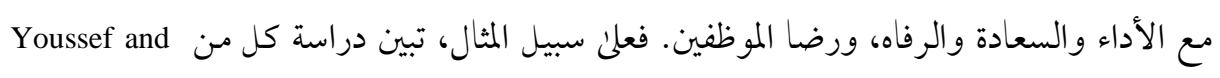


Luthans الموظفين ومستوئ الأمل والنهوض يرتبط موجبا بأداءهم ورضاهم، والنية للاستمرار بالعمل، كما توصلت دراسة Legal and Meyer (2009)، أن الكفاءة الذاتية لها علاقة بمستوى الأداء والنمو المهني لدئ الموظفين. الدراسات التي تناولت العلاقة بين جودة حياة العمل والالتزام التنظيمي تناولت دراسة Hong; Kok \& Suraini (2010) العلاقة بين جودة حياة العمل والالتزام التنظيمي، وضغط العمل، ورضا العمل، وأجريت علن 110 مدرسين في مدرسة حكومية بماليزيا. وأظهرت النتائج وجود علاقات معتدلة بين جودة الحياة المهنية والالتزام التنظيمي، والإجهاد، و الرضا الوظيفي، وأن الالتزام بالعمل وضغوط العمل و الرضا الوظيفي لم تكن مرتبطة ارتباطا كبيرا. واستهدفت دراسة Asgari \& Dadashi (2011) التعرف علن العلاقة بين جودة حياة العمل، والالتزام التنظيمي لدئ موظفي بنك ملي في مازاندران، وطبقت علئ عينة مكونة من(210)، واستخدمت الدراسة معامل ارتباط بيرسون، ومعامل الانحدار Stepwise، وتم التوصل إلى أن هناك علاقة بين جودة حياة العمل، والالتزام التنظيمي (r=0.183)، كما توجد علاقة بين جودة حياة العمل وأبعاد الالتزام التنظيمي الثلاثة (العاطفي والمستديم والمعياري). فيها توصلت دراسة البلبيسي (2012) التي أجريت على عينة (265) موظف تم اختيارهم بطريقة العينة الطبقية العشوائية من (ror ) منظمة دولية إلى وجود علاقة موجبة بين أبعاد جودة الحياة، ومستوى الالنزام التنظيمي ، كما أثبتت دراسة Ahmadi; Salavati \& Rajabzadeh (2012) التي طبقت علن( 343) موظفا بكردستان، وجود علاقة قوية بين جودة حياة العمل ومكوناته بمستوئ الالتزام التنظيمي. كما استهدفت دراسة Farid; Izadi; Ismail\& Alipour (2014) فحص العلاقة بين جودة حياة العمل، والالتزام التنظيمي لدئ أعضاء هيئة التدريس بجامعة البحث العامة بهاليزيا علن عينة مكونة من (315)، وتم استخدام الارتباط والانحدار الخطي، وتوصلت الدراسة أن هناك علاقة بين نوعية حياة العمل، و الالتزام التنظيمي. 
ودراسة Hussain \& Saleem (2014) توصلت إلى أن جودة حياة العمل لها تأثير إيجابي قوي علن الاحتفاظ بالموظفين؛ إلا أن الرضا الوظيفي والمشاركة والالتزام التنظيمي لا تتوسط العلاقة بين جودة حياة العمل والاحتفاظ الموظفين. وفي دراسة Kee; Ahmad; bin \& Abdullah) استهدفت العلاقة بين المكافآت المالية والالتزام التنظيمي بين العاملين في القطاع المصرفي في ماليزيا، علن عينة (150) عاملا، وأظهرت وجود علاقة بين التعويضات المالية مثل الرواتب والعلاوات والأجور المستحقة بالالتزام التنظيمي، إضافة إلى أن الأجر القائم علن الجمدارة هو العامل الأكبر في التأثير على الالتزام التنظيمي بين العاملين في البنك. كما استهدفت دراسة Ojedokun; Idemudia \& Desouza (2015) دور الهيبة الخارجية المتصورة في العلاقة بين جودة حياة العمل، والالتزام التنظيمي بين موظفي القطاع العام في غانا، تم تطبيقها على عينة من ( 137)، وأظهرت النتائج أن جودة حياة العمل ترتبط ارتباطا إيجابيا بالهيبة الخارجية المتصورة، والالتز ام التنظيمي، كما تتوسط الهيبة الخارجية بشكل جزئي العلاقة بين جودة حياة العمل، والالتزام التنظيمي. الدراسات التي تناولت العلاقة بين رأس المال النفسي والالتزام التنظيمي دراسة Zhong (2007) استهدفت التعرف علن تأثير رأس المال النفسي علن أداء العمال، والالتزام التنظيمي على (67) مشرفا، توصلت إلى أن رأس المال النفسي بأبعاده له آثر إيجابي على الأداء والالتزام التنظيمي، كما أثبتت دراسة (2009) Shahnawaz \& Jafri التي طبقت علن عينة مكونة من (160) مديرًا في المنظمات الحكومية والحاصة واستخدمت المعادلة البنائية ببرنامج AMOS أن رأس

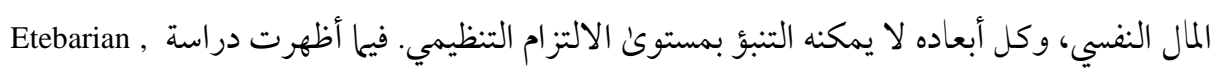
Tavakoli \& Abzari (2012) التي طبقت منظمة تجارية في إيران علن عينة من (132) ، أن الالتزام التنظيمي والأمل يرتبطا ارتباطا إيجابيا، ولكن الالتزام التنظيمي يرتبط عكسيا مع النهوض، كما لم يتم العثور علن علاقة بين التفاؤل، والكفاءة الذاتية مع الالتزام التنظيمي، وكانت العلاقة بين رأس المال 
النفسي والالتزام العاطفي فقط كبيرة، وأن الأمسل هو البعد الوحيد الذي يتنبأ بالالتزام التنظيمي بين أبعاد رأس المال النفسي بدرجة 0.335 والمرونة بدرجة 0.521.

كما أظهرت دراسة Sharifi \& Shahtalebi (2014)، أن هناك علاقة بين رأس المل النفسي، والالتزام التنظيمي بالتعليم في أصفهان بمعامل الارتباط (r=0.534)، وكذلك بين مكوناته الكفاءة الذاتية، والأمـل والنهوض والتفاؤل مع الالتزام التنظيمي. وفي دراسة لـ Han \& Chung (2015) لمعرفة أثثر رأس المال النفسي علن الالتزام التنظيمي علن عينة مكونة من (197) من الممرضات، توصلت إلى

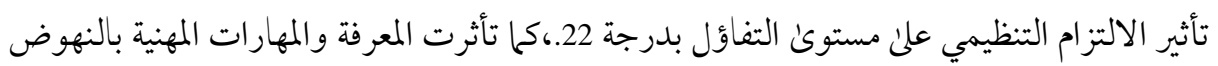
بدرجة 16.، فيها أظهرت دراسة (2016) Mohammadi; Vaisi \& Morad أن كل أبعاد رأس المال النفسي ترتبط ارتباطا طرديا بمستوى الالتزام التنظيمي، ما عدا بعد النهوض لدىن مدرسي التربية البدنية في ولاية كردستان.

كما توصلت دراسة Aminikhah; Khaneghah \& Naghdian (2016) التي استهدفت تقييم رأس المال النفسي، وعلاقته بالالتزام التنظيمي والرضا الوظيفي كمتغير وسيط لدئ موظفي التعليم، علن عينة مكونة من (150) موظفا، وتم استخدام معاملات الارتباط والمعادلة البنائية، إلى أن رأس المال النفسي يرتبط ارتباطا وثيقا بالالتزام التنظيمي، كما أن الرضا الوظيفي له أثر دال علن العلاقة بين رأس المال النفسي، والالتزام التنظيمي. تصني. تعليق عام على الدراسات السابقة: اتضح من عرض الدراسات السابقة أن: - بالنسبة للمسار (أ) اتفقت الدراسات على ارتباط رأس المال النفيي وأبعاده بجودة حياة العمل مثل دراسة Mortazavi; Yazdi \& Amin (2012) ودراسة Shabn, Parivash \& Nader

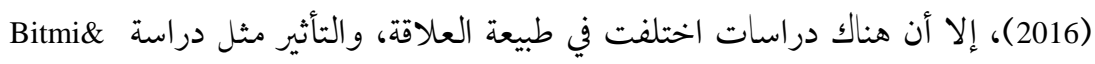
Ergeneli (2015)

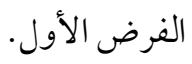


- أما المسار (ب) اتفقت الدراسات علن وجود علاقة ارتباطية موجبة بين جودة حياة العمل والالتزام التنظيمي مثل دراسة Hong; Kok \& Suraini و (2010) ودراسة Farid; Izadi; Ismail\& Alipour

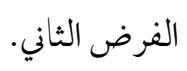

- فيما يخص المسار (ج) اختلفت الدراسات التي تناولت العلاقة بين رأس المال النفسي، وأبعاده بمستوئ الالتزام التنظيمي حيث أثبتت بعضها وجود علاقة وتأثير مثل دراسة Sharifi \& Shahtalebi النفسي على التنبؤ بمستوى الالتزام التنظيمي مثل دراسة Etebarian, Tavakoli \& Abzari (2012)، ودراسة (2016) Mahammadi et al التنظيمي؛ بناء عليه تم صياغة الفرض الثالث. - استخدمت الدراسات المعادلة البنائية، والارتباط والانحدار الخطي للمعالجة الإحصائية في تحليل العلاقات، والأثر والدور الوسيط، إلا أن الدراسة الحالية استخدمت نموذج العمليات الكلية لـ Andrew Hayes بالإضافة لمعاملات الارتباط والانحدار الخطي. - - تراوحت العينات في الدراسات بين63 و 400 مفردة، فيما اقتصرت الدراسة الحالية علن عينة قدرها (51) ؛ لصغر مجتمع الدراسة، وهو ما سيتم تبريره في إجراءات الدراسة.

الخلفية النظرية

يتناول هذا الجزء من الدراسة تأطيرا مفاهيميا لمتغيرات الدراسة من خلال التعرف على الخلفية النظرية والفلسفية وأبعاد جودة حياة العمل، وعرضا تفصيليا لرأس المال النفسي ومكوناته الأربعة الأمل والنهوض والكفاءة الذاتية والتفاؤل، ثم تحليل مفهوم الالتزام التنظيمي، والنواتج المترتبة علن مستوياته، ويالنهاية عرض لأبعاده الأشهر، وهي الالتزام العاطفي والمعياري والمستمر. 
Psychological Capital المحور الأول: رأس المال النفسي لم يعد رأس المال التقليدي هو العامـل الأساسي لتحقيق الميزة التنافسية المستديمة، كها لم تعد الموارد التقليدية تدعم المنظات للحصول على مصادر تمكنها للوصول لهذه الميزة، بـل أصبح المورد البشري هو الأهم لتحقيق المعادلة التنافسية في ضوء الشر اسة الدولية في التنافس بين الجامعات؛ الأمر الذي أدى' بالباحثين إلى البحث عن تفسيرات تساعد في تحسين الحالة النفسية للأفراد بها ينعكس على أدائهم الوظيفي، وبعض المفاهيم الأخرى مثل شعورهم بالملكية للمنظمة والتماثل التنظمي، والالتزام التنظيمي، من هنا ظهر مفهوم رأس المال النفسي. ويوضح \&hen, Gully, Whiteman, \& (2000) Kilcullen أنه يمكن فهم رأس المال النفسي من خلال التساؤل عن " من أنت؟" و "ماذا تستطيع أن تصبح من حيث التنمية الإيجابية، كما يشير للحالة النفسية الإيجابية للفرد والخاصة بالنمو والتطور، وهي حالة تشبه القدرة الاستيعابية النفسية ترتبط بشكل دقيق بمجموعة من المواقف والمهام، وتميل للتكيف مع الوقت. الأصول النظرية لرأس المال النفسي: نشأ مصطلح رأس المال النفسي من مجموعة من النظريات في علم النفس تناول هذه الأصول Luthans et al., 2005) يمكن تناوها في أربع نقاط كالتالي:

ا - أنه يعتمد على نموذج علم النفس الإيجابي وهو من فروع علم النفس يهتم بتحسـين الأداء النفسي الوظيفي للإنسان، حيث يركز على بحث محددات السعادة البشرية والتركيز على العوامـل التي تفضي إلى تمكين الإنسان من العيش حياة مُرضية يحقق فيها طموحاته، ويوظف فيها قدراته إلى أقصن حد للوصول للرضا عن الذات، وعن الآخرين، وعن العالم بصفة عامة (أبوحلاوة، 2014). كما يهتم علم النفس الإيجابي بتحقيق فهـم، وتحديد العوامل التي تمكن الأفراد، أو المجتمعات من الازدهار، بتوظيف أفضل مـا في الطرق العلمية لدراسة مشـكلات البشـر وتخليصهم من صور المعاناة النفسية بالتركيز على ما مكامن 
القـوة والفضـائل الإيجابية؛ مما يؤدي إلنى فهمه لذاته وحثـه علن تغيير طرق تفكيره السلبي في ذاته وفي الآخـرين. (Seligman\& Csikszentmihalyi, 2000) r- - أنه يشمل المواقف النفسية المرتكزة إلى السلوك التنظيمي الإيجابي: حيث يرىن كل من Greenberg \& Baron السلوك الإنساني في المنظمات، بالدراسة النظامية للفرد والجماعة والعمليات التنظيمية، وأن الهدف الأساسي لهذه المعرفة هو زيادة الفعالية التنظيمية وزيادة رفاهية الفرد. ووفقا لـ Luthans والقدرات النفسية ذات التوجه الإيجابي الموجودة لدى الموارد البشرية التي يمكن قياسها وتطويرها و إدارتها بفعالية لتحسين الأداء في مكان العمل ". ب- - أنه يذهب فيما وراء رأس المال البشري، ورأس المال الاجتحاعي: حيث يتعلق رأس المال البشري بالقدرات البشرية لدنا المنظمة القادرة علن توليد رأس المال الفكري من خلال كفاياتهم واتجاهاتهم، حيث تتمثل الكفايات في المهارات ومستوى التعليم لديهم، فيها تتمثل الاتجاهات في الأبعاد السلوكية لعمل الموظفين، فيا تتركز الرشاقة الفكرية علن الابتكار

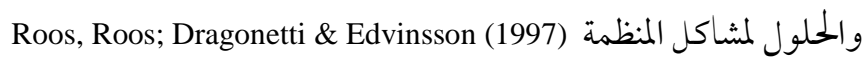
ع - أما رأس المال الاجتماعي فيمكن تناوله من جانبين هما رأس المال الاجتماعي الداخلي ويتمثل في قدرة الأفراد على نشر المعرفة داخل المنظمة، والعلاقات بين الأفر اد داخل المنظمة ومدئ الثقة المتبادلة في أداء أعحال المنظمة، أما رأس المال الاجتماعي الخارجي: يتمثل في

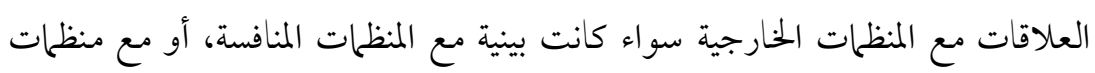
أخرى من مجالات أخرى تدعم عمليات التوريد وغيرها من مدخلات المنظمة. 0- يتألف من الاستثمار والتطوير المؤديان لتنمية الأداء وتحسين الميزة التنافسية: حيث أنه كما تم

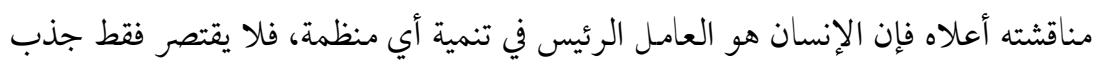

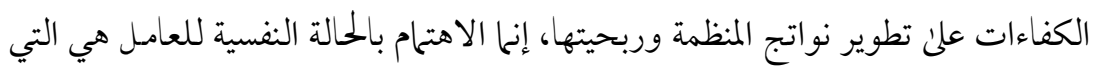


قد تخلق ميزة تنافسية للمنظمة من خلال إحساس العامل بملكيته لأعحال المنظمة وانتحاه،

$$
\text { وولانه هلا. }
$$

مكونات رأس المال النفسي: يمكن تمييز مكونات رأس المال النفيي كما تناولها Luthans et al (2007, 3) في أربعة مكونات هي الكفاءة الذاتية، و التفاؤل، والأمل، والنهوض علني النحو التالي: الكفاءة الذاتية Self-efficacy: يمكن تعريفها بأنها "قناعة الفرد وثقته في قدراته علن حشد دوافعه ومصادره المعرفية، وقدراته الأدائية اللازمة لتنفيذ مهمة محددة في سياق معين بنجاح ") Stajkovic \& Luthans, 1998, 66 وبالتالي فهي تمثل توقع عضو هيئة التدريس بمرونته في حل المشكلات، ومو اجهة المشكلات الجديدة. كما يرئ Luthans, et al يتم تطويرها عندما يمر الفرد بتجربة النجاح، أو ما يسمى التمكن من المهمة، والثانية يمكن تطوير كفاءة الأفر اد حينما يتعلمون بطريقة النمذجة، والثالثة تتطور الكفاءة الذاتية من خلال اقتناع الأفراد الذين يتمتعون بالاحترام به من خلال تغذيتهم الراجعة لأداءه (الاقناع الاجتماعي)، والرابعة تتطور من خلال الإثارة والصحة النفسية. كما يتميز الأفراد ذوي الكفاءة الذاتية بخمسة سلوكيات

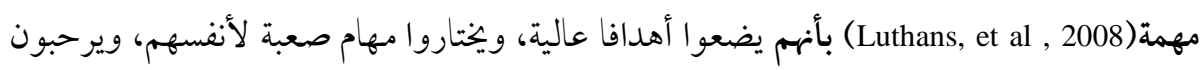
ويتطورون بالتحدي، كما أن الدافعية الذاتية لديهم عالية، ويستثمرون الجهد اللازم لتحقيق أهدافهم، ولديهم قدر كبير من المثابرة عندما تواجهم عقبات، كما يشير Bandura (1994) أن الكفاءة الذاتية المدركة تتعلق بمعتقدات الناس في قدراتهم علن ممارسة السيطرة على أدائهم وعلى الأحداث التي تؤثر علن حياتهم، وتؤثر الثقة بالكفاءة الشخصية علن خيارات الحياة، ومستوكن التحفيز، ونوعية الأداء، و القدرة علن الصمود أمام الشدائد، والتعرض للضغوط و الاكتئاب. 
لبناء الثقة أو الكفاءة الذاتية للفرد اقترح Tams(2008) أربعة عوامل مشتر كة:

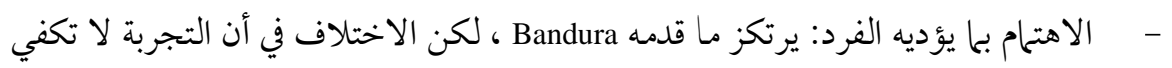

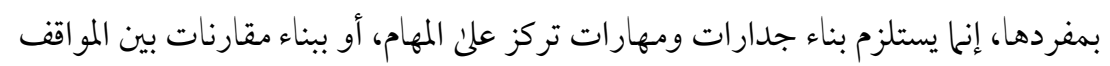

$$
\text { الحالية والخبرات السابقة لإيجاد معايير مقارنة مرجعية ذاتية. }
$$

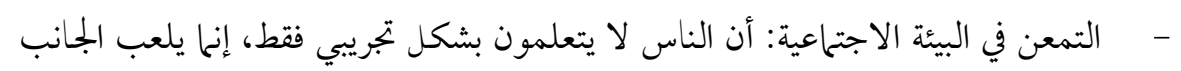

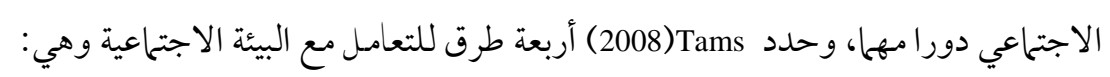

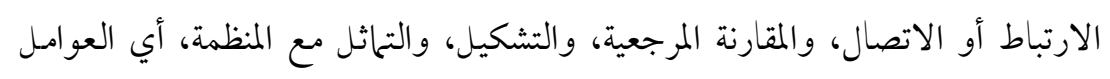

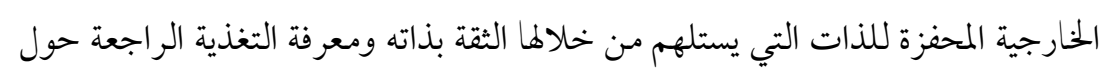
قدراته ومهار اته. - - الانعكاس علن ما يفعله الفرد: من خلال إعادة ترجمة مضادة للتغذية الراجعة السلبية،

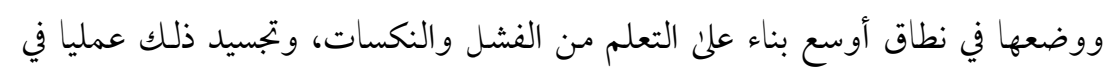
حياتهم الشخصية والوظيفية. - - اتخاذ مواقف تجاه البيئة: قد تأتي استجابة الأفراد للتغذية الراجعة السلبية من خلال الخاذ

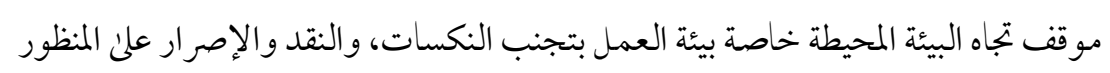

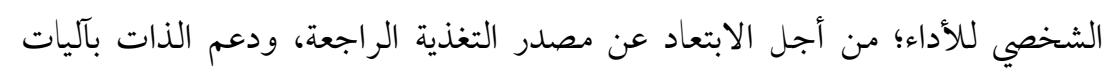
شخصية.

من خلال عرض ما سبق يتضح أن الكفاءة الذاتية، أو الثقة تستند إلى الممارسة، والخبرة التي

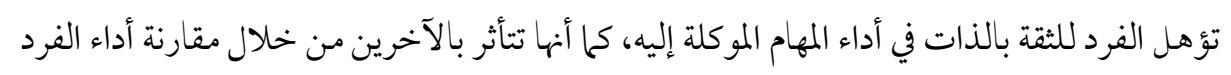

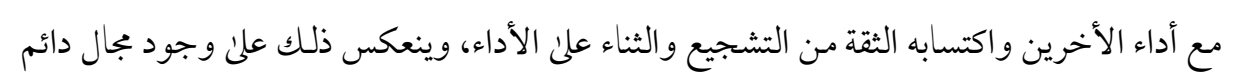
للتحسين في سلو كيات الفرد التي تدعم ثقته في أداءه.

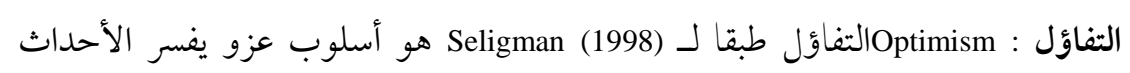

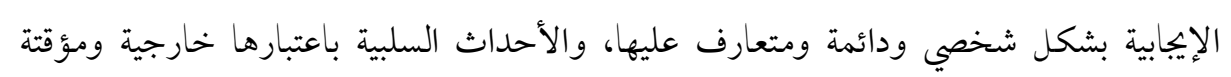


ومقصورة علن الموقف، فالتفاؤل ليس ججرد التنبؤ بأن الأمور الجيدة ستحدث في المستقبل، إنما يعتمد

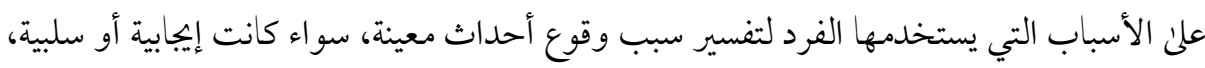
في الماضي أو الحاضر أو المستقبل. كتاب رأس المال النفسي)

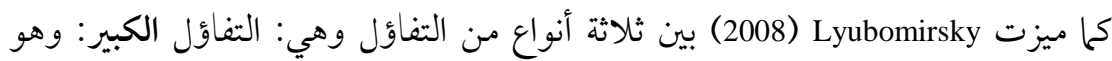

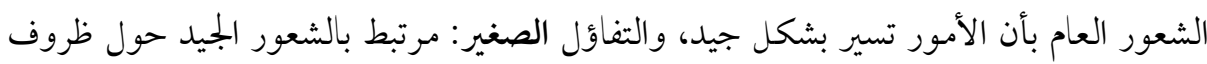

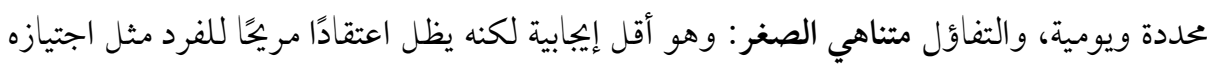

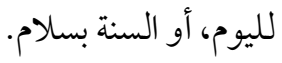
أما Seligman (1998) فقد قسم التفاؤل إلى ثلاثة أبعاد: الاستمرارية: يعتقد المتفائلون أن

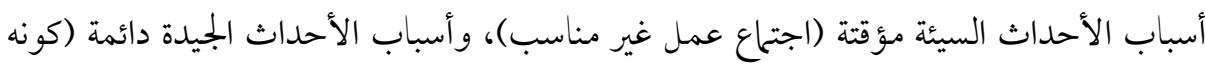
شخصية مثقفة وخبيرة)، فيا يعتقد المتشائمون عكس ذلك: الأحداث السيئة لها أسباب دائمة والأحداث الجيدة ها مؤقتة، والتغلغل pervasiveness: يعتقد المتفائلون أن أسباب الأحداث السيئة

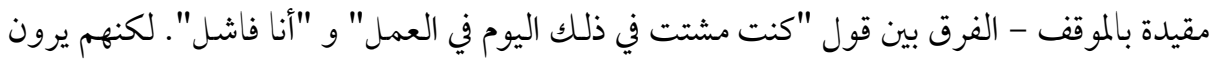

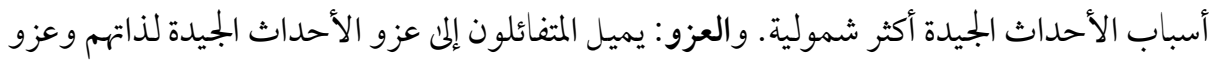

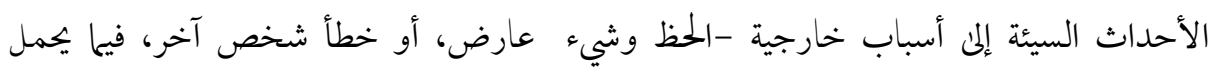

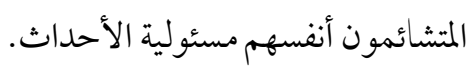

الأمل Hope: يركن Synder (1995) أن الأمل هو التوجه نحو الأهداف، كما أنه هو اعتقاد

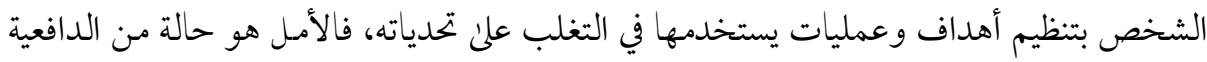

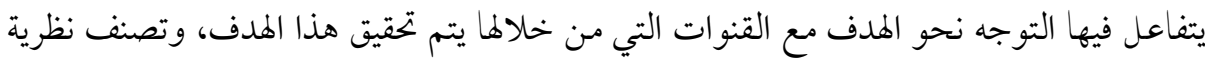

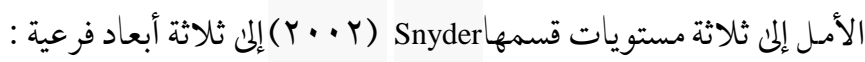

وضع الأهداف: تتنوع حسب أهميتها من أهداف خاصة بتحقيق الحاجات الأساسية مثل

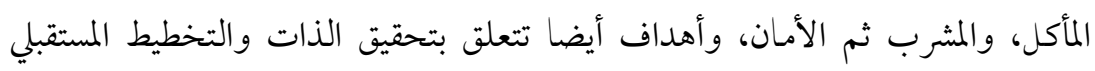
ل لتطوير ذاته، وتحقيق مكانة مرضية.

http://dx.doi.org/10.29009/ijres.1.4.4 
تطوير استراتيجيات خاصة للوصول للهدف (pathways thinking): بالتفكير في مسارات

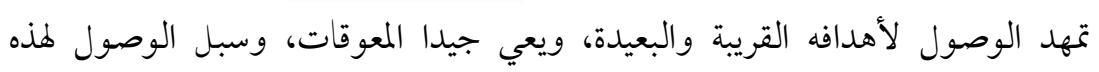
الأهداف، إضافة إلى تفكيره في السبل البديلة للوصول للهدف. المبادرة واستدامة الدافعية في استخدام تلك الاستراتيجيات (agency thinking) وهذه متعلقة بتجديد الرغبة في الوصول للهدف، وتقليل مستوئ اليأس. وقد أسس مقياسه للأمل بناء علن هذه المحاور وتكون المقياس من ستة معايير تغطي الأبعاد الثلاثة الماضية، وتستند الدراسة الحالية إلى هذا المقياس في الجانب الميداني لقياس بعد الأمل. النهوض أو كفاءة المواجهة Resiliency: عرف charney (2004, 205) النهوض علن أنه "عملية التكيف الجيد في حالة الصدمة، أو المأساة أو أي حدث آخر ذات علاقة بالتوتر"، وأضاف أن المرونة

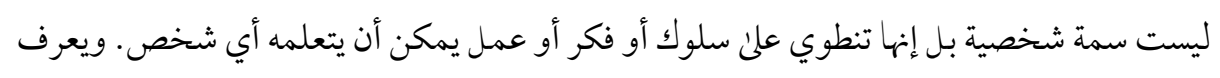
كل من Keye \& Pidgeon (2013, 1) النهوض بأنه "قدرة الفرد على التعافي من أحداث الحياة المؤلمة، والصعبة مع زيادة المعرفة بأساليب التكيف مع الحالات السلبية المماثلة في المستقبل، ويستندا في

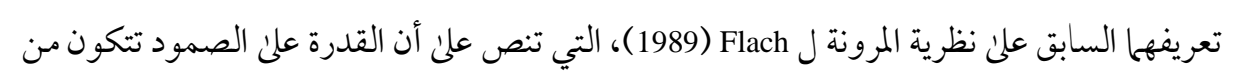
نقاط القوة النفسية اللازمة لإحداث التغيير. تستند نظرية المرونة إلى "قانون الاختلال، وإعادة

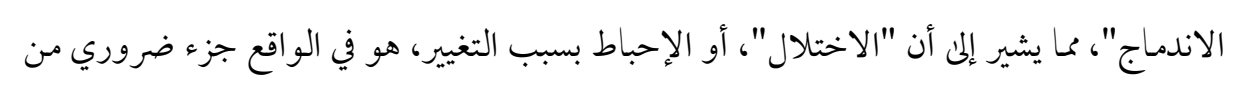
التعلم للتعامل مع أحداث الحياة الضاغطة. تفترض نظرية فلاش أن التحديات المؤقتة هي فرص جيدة للتعامل مع الآلام القديمة، واكتشاف آليات جديدة للتكيف، وإعادة تنظيم منظور الشخص عن الحياة، وتسمى هذه العملية إعادة الاندماج وتشمل إعادة تشكيل رؤية الشخص عن العالم وعن ذاته (Flach,1989). وبالثالي فالنهوض يتمثل في قدرة الفرد المتعرض للمشكلات والمخاطر علن الاستفاقة واستعادة النجاح بالتغلب علن هذه المشكلات والتحديات، كما يتعلق النهوض بالقدرة علن الهدوء والتعامل مع الظروف عند مواجهة مو اقف سلبية 
وخخاطر والتغيرات الجوهرية، وهو مصطلح لعملية معقدة تستديم طوال حياة الشخص، والتي تجعله إلها يناهض في المر احل غير المؤكدة ليتفاعل مع بيئته بشكل جيد وهريد.

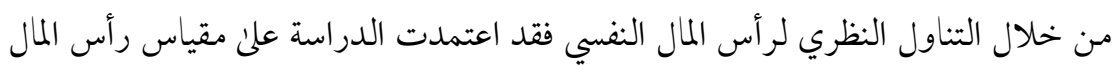

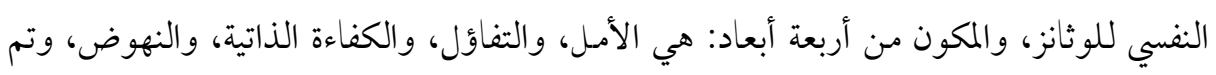

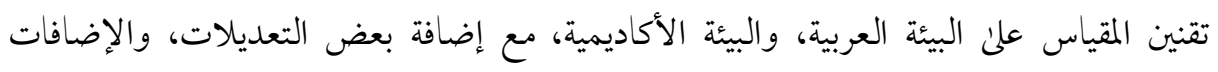

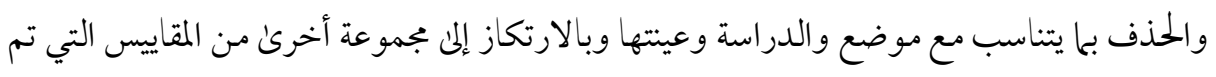

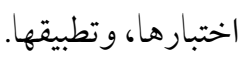

المحور الثاني: جودة حياة العمل يتناول هذا المحور تأطيرا نظريا لجودة حياة العمل من حيث المفهوم من خلال مر اجعة

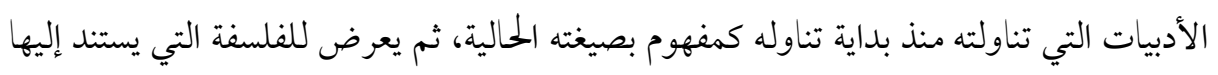
المفهوم، والنظرية التي تم تأسيس المفهوم عليها، وبالنهاية عرض لأبعاد جودة حياة العمل التي تلني

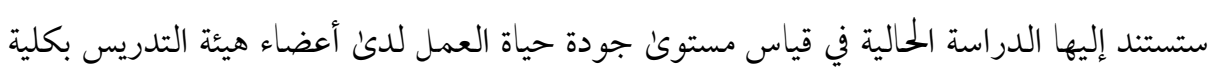

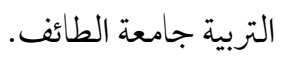

الأصول الفلسفية لجودة حياة العمل: يرئ Mullins (1996) أن الاهتمام الذي حظيت به جودة

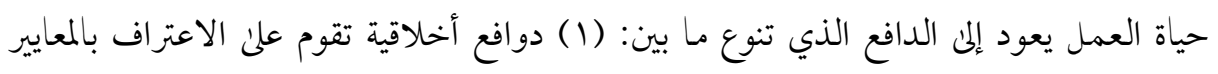

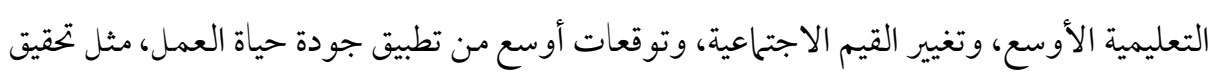

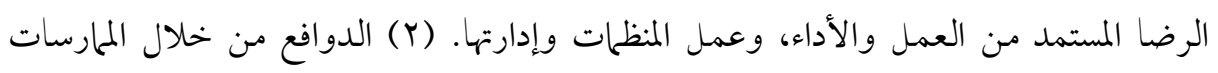

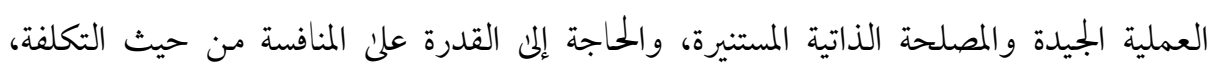
ومحاولات التغلب علن مستويات عالية من التغيب، ودوران الموظفين، وعدم الرضا، والعقبات

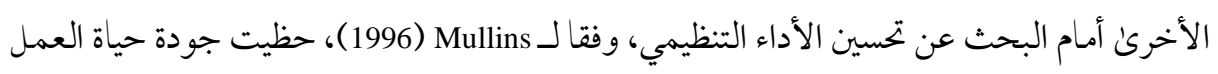

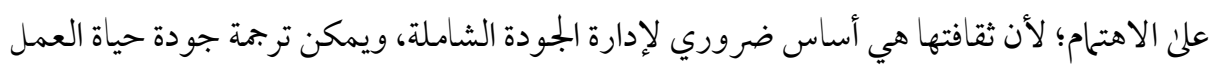

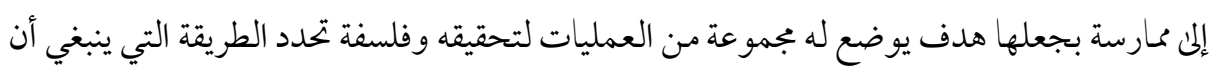


يدار بها الناس. كما أن جودة حياة العمل لها فلسفة واضحة تعتبر أن الأفراد هم أهم مورد، ليتم معاملتهم بطريقة محترمة في المنظمة -حيث أنهم جديرون بالثقة، ومسؤولون، وقادرون علن تقديم مساهمات قيمة.

الأصول النظرية لجودة حياة العمل: بالنظر إلى جودة حياة الفرد بشكل عام فإنها ترتبط بأسلوب حياة الفرد، وبها يقوم به من نشاطات للسيطرة علن ما يجري حوله ومستقبله (حسين، 2003، 37)،كما أن هناك العديد من المعوقات التي تمنع الفرد من الوصول إلى الإحساس بجودة الحياة، الضغوط الناتجة عن الصراع الداخلي الذي يشعر به نتيجة ضعف الإنجاز، (إبراهيم ؛ و صديق

.) (278، 20066

فيما يخص جودة الحياة في العمل، وخاصة في المجال الجامعي، فإنها تتمثل في مجموعة من الأبعاد تناولتها الأدبيات منذ ظهور المفهوم في بداية السبعينيات من القرن العشرين حيث قدم لأول مرة عام 1972 خلال المؤتمر الدولي لعلاقات العمل، ونال اهتحامَاً كبيراً بعد أن قامت مؤسسات: Hian \& Einsteion , ) ببرامج لتحسين وإصلاح العمل United Auto workers and General Motors 1990). كما يعرف Dargahi and Yazdi (2007, 630 جودة حياة العمل علن أنها "برنامج شامل يستهدف تحسين الرضا و التعلم المرن في بيئة العمل ومساعدة الموظفين في إدارة التغيير بشكل جيد"، كما أنها "خلق ظروف عمل مرغوبة من خلال تقديم مكافآت وأمان وظيفي وفرص نمو مهنية تقود إلى دعم الموظفين وزيادة رضاهم" (Nanjundeswaraswamy and Swamy, 2013, 201)، وتتطلب جودة حياة العمل مناخا تنظيميا وهيكليا يدعم ويقدم آليات لتحسين الإجراءات القائمة

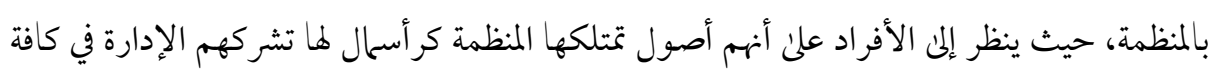

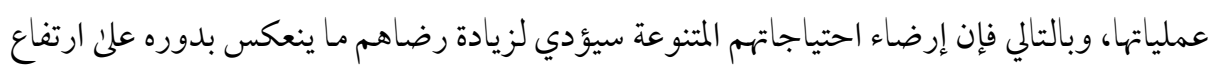
معدل أدائهم الوظيفي) (Kanten, 2014) بناء علن ما سبق، يلاحظ أن جودة حياة العمل، تتمثل بجانبين أساسيين، أولها تنمية إدارة

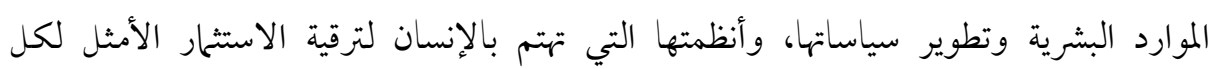




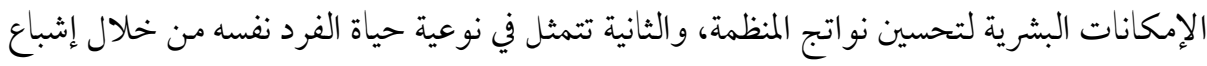

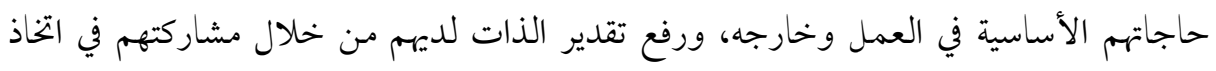
القرارات المصيرية التي تخص المنظمة.

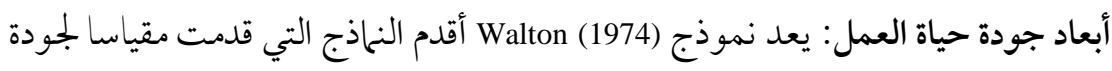

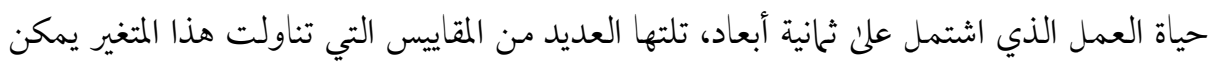

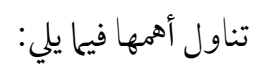
تناوها Nadler and Lawler (1983) من خلال أربعة محاور تمثلت في: المشاركة: وذلك بدمبج الأفراد من كافة المستويات في صناعة القرار. الثقة Trust: من خلال إعادة تصميم الوظائف، شكال

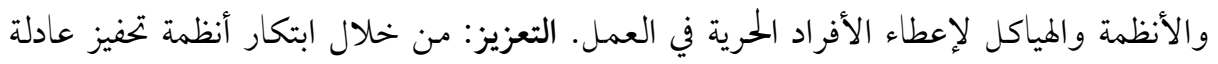

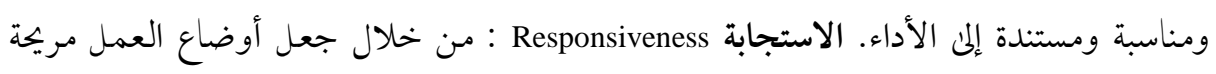
ومساعدة في تلبية احتياجات الموظف.

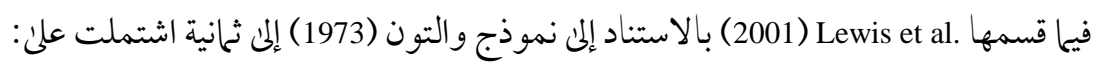

$$
\begin{aligned}
& \text { • الدعم المتبادل بين الموظف وزملائه ورؤساءه. } \\
& \text { • فرق العمل والاتصال الفعال داخل بيئة العمل. }
\end{aligned}
$$

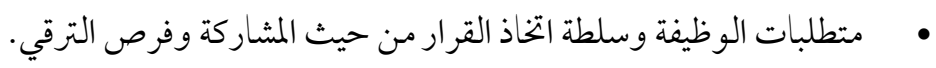

الرعاية الصحية والاجتماعية التي توفرها المنظمة.

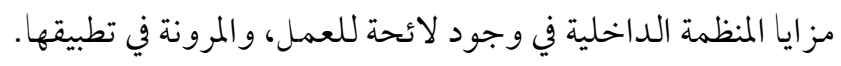
المكاسب والحوافز التي تتوفر للمنظمة وتميز ها عن منافسيها.

$$
\text { التنمية المهنية وفرص النمو من تدريب وزيار ات وبحث علمي. }
$$

الانطباع العام عن المنظمة من حيث صورتها الحارجية وتميزها الداخلي.

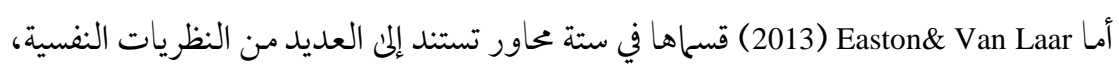
والإدارية يمكن تلخيصها: 
الرضاعن المهنة: يتعلق بالرضاعن العمل، والفرص المهنية المتاحة للموظف، حيث يقيم

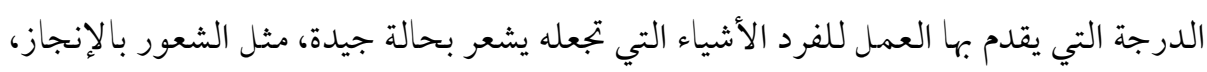
والتقدير الذاتي، وانجاز كل الأمور الممكنة.

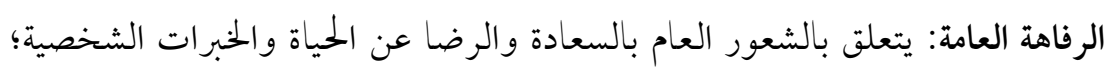

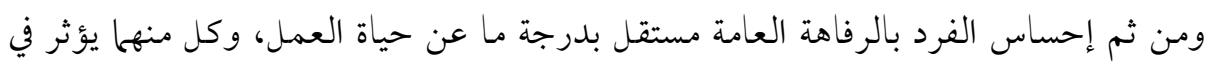

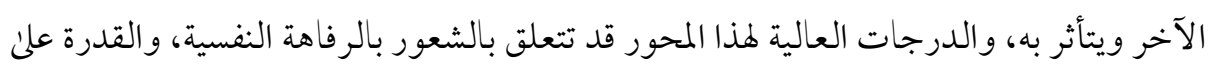

$$
\text { التكيف مع التغيير والتوافق مع صعوبات العمل. }
$$

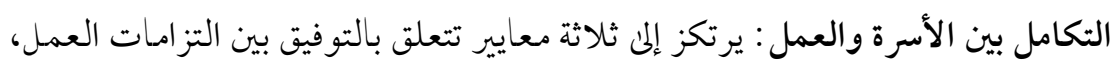

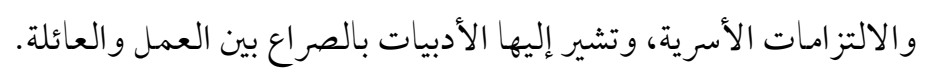

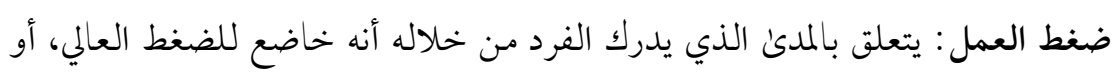

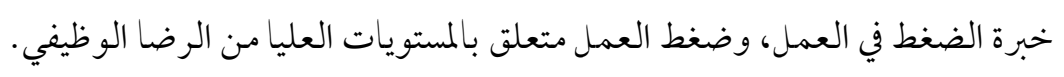

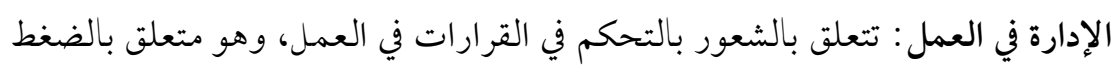

$$
\text { مع شعور التحكم، أو السيطرة في العمل، والرضا الوظيفي والصحة والرفاهة. }
$$

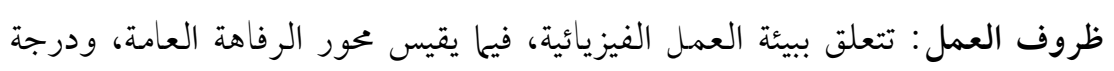

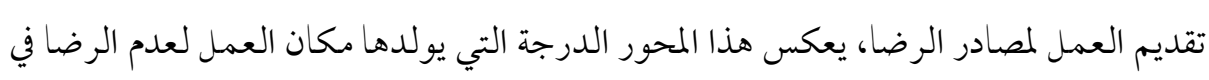

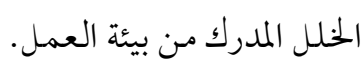

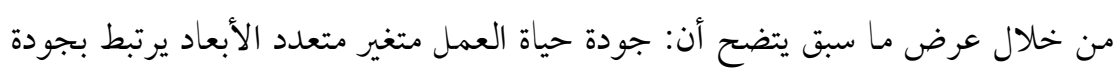

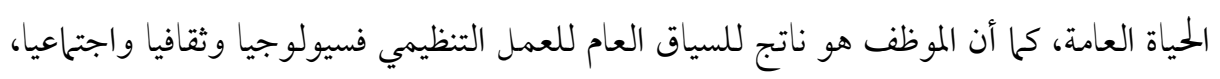

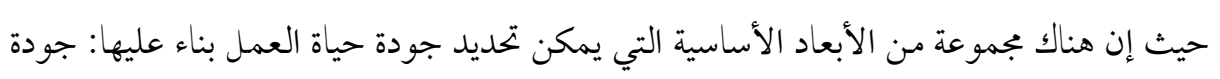
الحياة الشخصية: متعلقة بالفرد ذاته، حياته الخحاصة، ومستواه العلمي، وخبراته الحياتية، وإتقان أداء

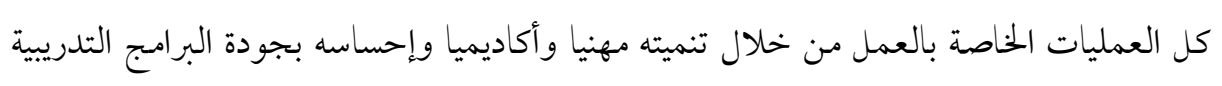

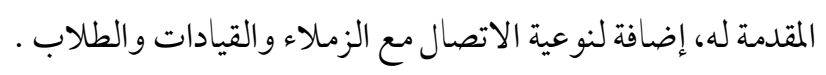




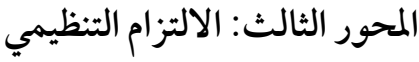

أدئ تطور الفكر الإداري في القرن العشرين، وظهور المدرسة السلوكية التي اهتمت بالطريقة

العلمية لدراسة السلوك الإنساني بمجالات علم النفس، وعلم الاجتماع إلى ظهور الالتزام التنظيمي

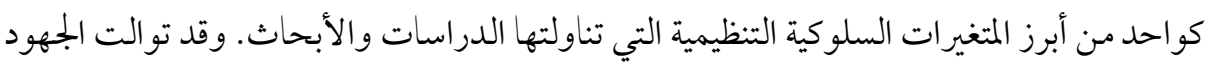

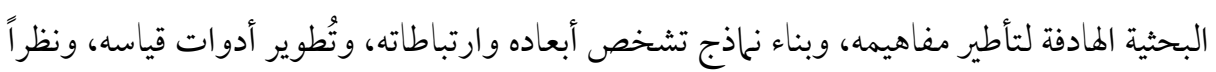

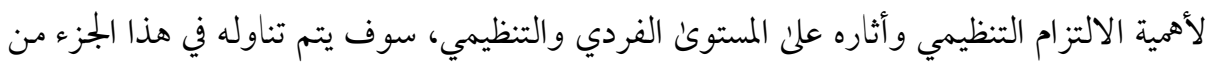

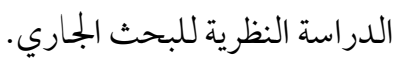

مفهوم الالتزام التنظيمي: الالتزام التنظيمي أحد أكثر المفاهيم صعوبة، حيث تتعدد مضامينه

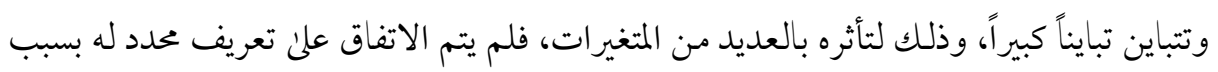

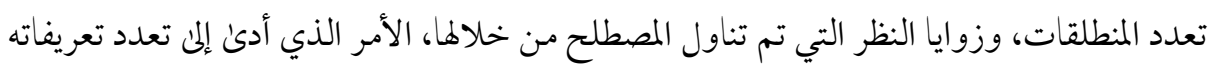
و تصنيفاته. وفيما يلي بعض هذه التعريفات حسبا وردت في الأدبيات الأجنبية والعربية.

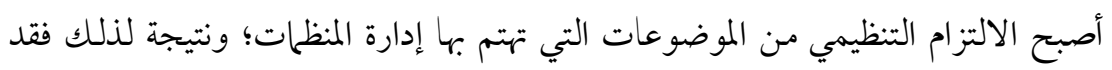

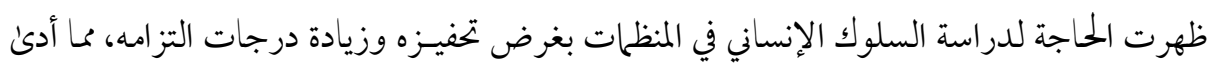
إلى إجراء الكثير من الدراسـات وحظي موضوع الالتز ام التنظيمي باهتحام الكثيـرين مسن المشتغلين

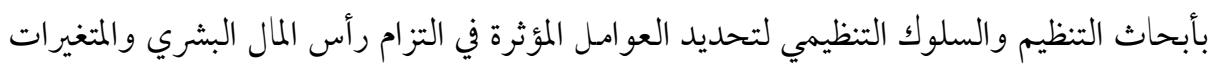

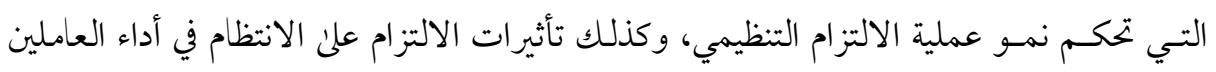

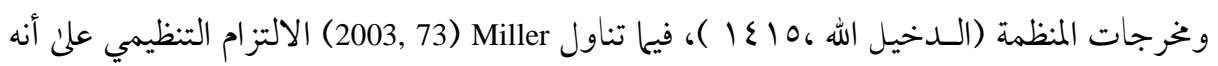

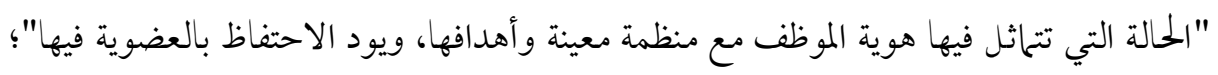

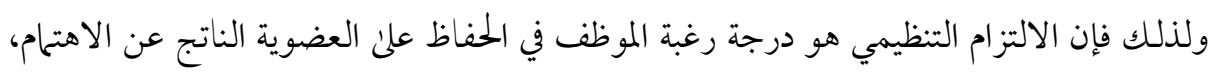
والترابط مع أهداف المنظمة وقيمها. يمر الالتزام التنظيمي عبر مراحل للوصول لحالته النهائية وهي: مرحلة الإذعان: أي الطاعة الطان

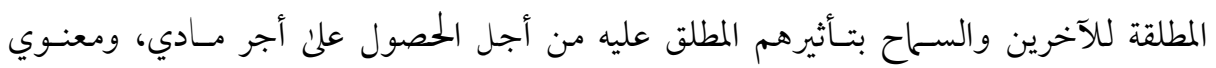




\section{/ محمود سيد علي أبو سيف

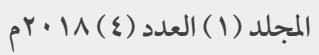

بالرضو خ للأوامسر، و التعليات دون تفكير، أو مناقشة، ومرحلة الاندماج مع الذات: فيها يقبل الفرد تأثير الآخرين من أجل تحقيـق الرضا الدائم له في العمل، وتحقيق الانسجام مع الذات، والشعور بالفخر والكبريساء لكونه ينتمي للمنظمة، ومرحلة التهاثل مع هوية المنظمة: وهي المرحلة التي تشير إلى

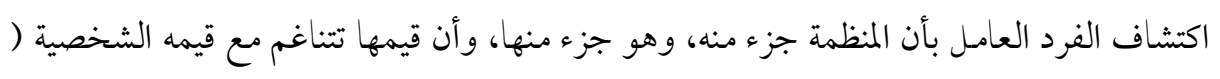
حمادات، 2006). الأثار المترتبة على مستويات الالتزام التنظيمي :هناك مجموعة من الآثار التي قد تترتب على مستوئ الالتز ام التنظيمي علن مستوكئ الفرد والمنظمة وقدصنفها (1987) Randall على أنها تتراوح بين منخفضة ومتوسطة وعالية، وذكر أن هذه الآثار قد تكون إييابية أو سلبية علن مستوكئ الفرد والمنظمة: يمكن عرضها بالجدول التالي:

جدول (1) يبين الأثار المترتبة علن مستويات الالتزام التنظيمي

\begin{tabular}{|c|c|c|c|c|}
\hline \multicolumn{2}{|c|}{ على مستوى المنظمة } & \multicolumn{2}{|c|}{ على مستوى الفرد } & مستوى \\
\hline سلبي & إيجابي & سلبي & إيبابي & الالتزام \\
\hline الدوران الكبيرللموظفين-تناقص العمل - التظيمي - النشاط غير الشرعي الولاء & سر المنظمة والمعطلين للعمل - من الموان العمال الأضعف في & التطع المحتمو المهني- التكلفة نتيجة & فعال اللموارد البشرية - الإبتخدام - الابتكار - & منخفضة \\
\hline 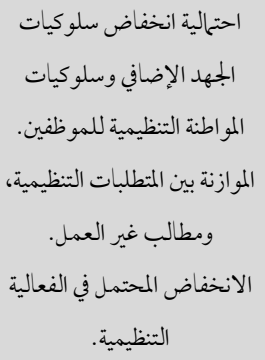 & محدودةدة مدة عمل الموظفين-نية & محدودية فرص الترقي والتطور & 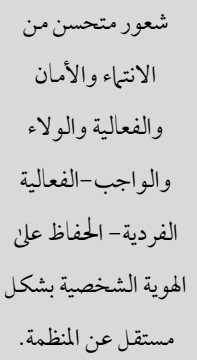 & متوسطة \\
\hline
\end{tabular}


Volume (1) No. (4) 2018

\begin{tabular}{|c|c|c|c|c|}
\hline \multicolumn{2}{|c|}{ على مستوى المنظمة } & \multicolumn{2}{|c|}{ على مستوى الفرد } & مستوى \\
\hline سلبي & إيجابي & سلبي & إيجابي & الالتزام \\
\hline 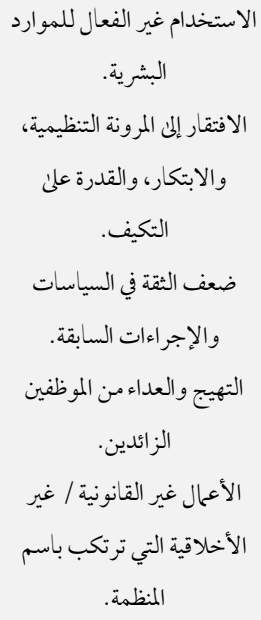 & 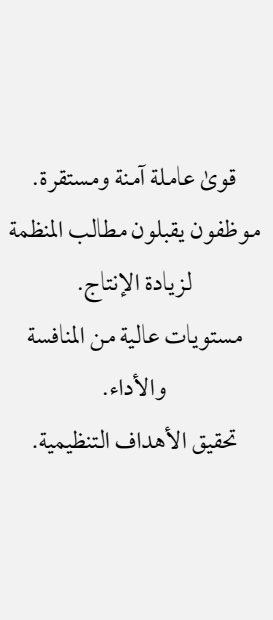 & 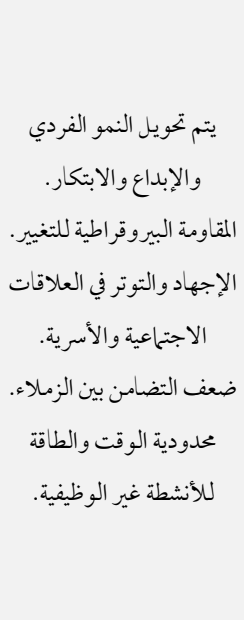 & تعزيز الفريز الترقي الوظيفي والمكآتآ. & مرتفعة \\
\hline
\end{tabular}

يتضح من الجمدول أن المستويات العالية من الالتزام يمكن أن تؤدي أيضا إلى نتائج إيجابية، وسلبية للفرد والمنظمة، وعلئ الجانب الإيجابي، قد يتعرض الأفراد للتقدم الوظيفي الشخصي، أو زيادة الدخل، والنتائج الإيجابية للمنظمة قد تؤدي إلى قوة عاملة آمنة ومستقرة، وتعمل على تحقيق الأهداف والغايات التنظيمية، ومن ناحية أخرى، أظهر الجلدول أن المستويات المرتفعة من الالتزام التنظيمي ترتبط بالنتائج السلبية للأفر اد مثل محدودية فرص النمو والنجاح، وقد تكون بعض العو اقب السلبية علن المنظمة هي ضعف جدون الاستفادة من الموظفين، وانعدام المرونة والقدرة علن التكيف بالنسبة للمنظمة. أبعاد الالتزام التنظيمي: تناولت العديد من الدراسات الوصفية التجريبية مفهوم، وأبعاد الالتزام التنظيمي، إلا أن Allen and Meyer يعتبرا من الرواد في تناول المتغير تجريبيا، ويمكن توضيح أبعاده الثلاثة، وهي العاطفي، والمستدام، والمعياري يمكن عرضها علن النحو التالي: Allen and Meyer)

ا- الالتزام العاطفي Affective commitment: يتناول هذا النوع الالتزام المشاعري من جانب الموظف تجاه منظمته وعزمه علن المكوث فيها، كما يشير إلى تطابق الفرد مـع المنظمـة، 
وانهاكه فيها وارتباطه شعورياً بها ويعبر عن قوة رغبة الفرد في الاستمرار بالعمل في منظمة معينة؛ لأنه موافق على أهدافها، وقيمها ويريد المشاركة في تحقيق تلك الأهداف. ويشير الالتزام المهني العاطفي في بجال التعليم إلى أن أعضاء هيئة التدريس يرتبطون ارتباطا عاطفيا مع مهنة التدريس، وأهدافها، ومشاركتهم فيها فيها يتعلق بها يلي: تحفيزهم علن عدم إسقاط المهنة لرغباته الذاتية، والامتثال لهاو المساهم في نجاحها

ץ- الالتزام المستدام أو الاستمراري Continuous commitment : قائم علن إحساس الموظف بالخسائر التي سيتلقاها نتيجة تركه للمنظمة، كما يعكس التزام الموظف نحو منظمته الناتج عن تضحية شخصية منه، وضعف البدائل الوظيفية الأخرى المتاحة أمـامه، مما يجعله مستمر في ولاءه لمنظمته الحالية، وهو بمثابة استثار من جانبه في هذه المنظمة في ظل انعدام الفرص الوظيفية الأخرى أمـامه. فالعـاملون ذوي الانتمـاء المستمر العالي يبقون في المنظمة؛ لأن عليهم أن يفعلو ا ذلك (إمـا بسـبب إدر اك قلـة البدائل، أو بسبب الخوف من التضحية المر افقة لترك العمل في المنظمة). r- Normative commitment يشير إلى شعور الفرد بأنه ملتزم بالبقاء في

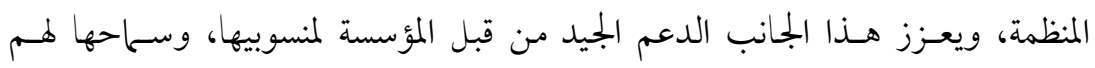
بالمشـاركة الفعالـة الإيجابية ليس في كيفية الإجراءات، وتنفيذ العمل فقط، بل بمساهمتهم في وضع الأهــاف، والتخطيط ورسم السياسات العامة للتنظيم (سلامة، 2003) بناء علن ما سبق عرضه اتجهت العديد من الدراسات إلى تشخيص عدد من الأبعاد للاستدلال بها عـن مستوي الالتزام التنظيمي، وتحديد طبيعة تأثيره في المتغيرات التنظيمية والسلوكية، ويعتبر Allen and Meyer رائدين في هذا الجحانب، من خلال إسهامها في تحديد الأبعاد الثلاثة للالتز ام التنظيمي. 


\section{إجر اءات الدراسة}

هدفت الدراسة الميدانية: تهدف الدراسة الميدانية إلى التعرف علئ مستوئ رأس المال النفسي

لدئ أعضاء هيئة التدريس بكلية التربية جامعة الطائف، والتعرف علن مستون جودة حياة العمل، ومستوئ الالتزام التنظيمي لديهم، إضافة لذلك تستهدف الدراسة التعرف علن العلاقة بين رأس الملال

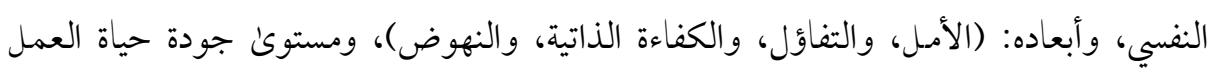

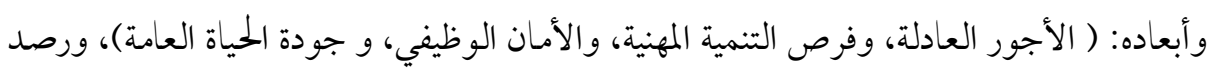
العلاقة بين رأس المال النفيي، وأبعاده بمستون الالتزام التنظيمي، ورصد العلاقة بين جودة حياة العمل وأبعاده بالالتزام التنظيمي. وبناء علن نتائج الدراسة الميدانية، وما تم تناوله في التأطير المفاهيمي لأبعاد الدراسة يتم اقتراح بجموعة من التوصيات التي قد تسهم في تحسين مستون جودة حياة العمل ما ينعكس علن تنمية رأس المال النفسي والالتزام التنظيمي لدئ أعضاء هيئة التدريس. بجتمع الدراسة والعينة: يتمثل بجتمع الدراسة في كل أعضاء هيئة التدريس بكلية التربية جامعة الطائف البالغ عددهم (120)، وتم تحديد حجم العينة المطلوب طبقا لما أورده (1975) Roscoe أن 30 - 500 مفردة ملائم لمعظم الأبحاث والدراسات، كما أنه يفضل أن لا تقل مفردات العينة عن عشرة أضعاف عدد متغيرات الدراسة، ومتغيرات الدراسة الحالية ثلاثة وبالتالي العينة الأفضل هل أعلى من 30، فهي طبقا لهذا تعد مناسبة، بناء عليه تم توزيع عدد (100) استبانة على أعضاء هيئة التدريس بالكلية، وتم استرجاع عدد( 55) استبانة، وتم استبعاد (4) لعدم قابليتها للتحليل إما لعدم جدية المبحوث في الإجابة ، أو عدم استكمالها لشروط ملئها لتتبقى (51) صالحة للتحليل بنسبة (72 ٪) وهي تعد نسبة استجابة جيدة لأغراض البحث. لتحديد خصائص عينة الدراسة، فقد تم تضمين قائمة الاستقصاء بجموعة من الاستفسارات التي تمثل معلومات عامة عن عينة الدراسة من أعضاء

هيئة التدريس في الكلية المشار إليها، وقد كانت النتائج كما يوضحها الجلدول التالي رقم (2): 


\section{د/ محمود سيد علي أبو سيف

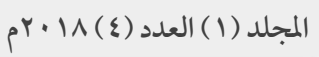

\begin{tabular}{|c|c|c|c|}
\hline النسبة .| & التكرار & الفئة & المتغير \\
\hline 47 & 24 & ذكر & \multirow{2}{*}{ النوع } \\
\hline 53 & 27 & أنثى & \\
\hline 100 & 51 & \multicolumn{2}{|c|}{ الإجمالي } \\
\hline 39 & 20 & محاضر & \multirow{4}{*}{ الرتبة العلمية } \\
\hline 43 & 22 & أستاذ مساعد & \\
\hline 10 & 5 & أستاذ مشارك & \\
\hline 8.0 & 4 & أستاذ & \\
\hline 100 & 51 & & \\
\hline
\end{tabular}

يتضح من الجدول رقم (2) أن نسبة الاستجابة من أفراد العينة الأعلى للذكور بنسبة (55٪)،

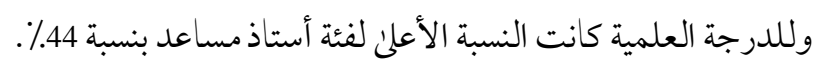

أدوات جمع البيانات: اعتمد الباحث علن قوائم الاستبانات التي أعدت لهذا الغرض المعتمدة على مقياس ليكرت الخحاسي اختياراته تتراوح ما بين عالية جدا، ومنخفضة جدا بوزن نسبي (0 - (1)، وقد تم تقسيمها إلى مجموعتين رئيستين، تختص الأولن بالبيانات الشخصية للمبحوثين، والثانية لموضوع البحث و تضم مجموعة من الأسئلة التي تتعلق بمتغيرات الدراسة الثلاث، وهي كالتالي:

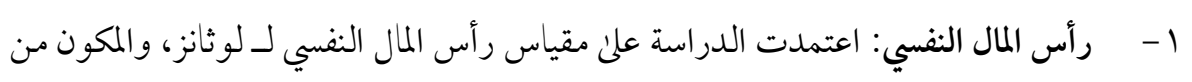
أربعة أبعاد، وهي الأمل والتفاؤل، والكفاءة الذاتية، والنهوض، وتم تقنين المقياس علن

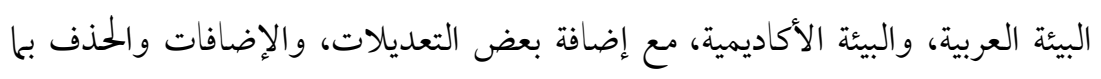
يتناسب مع موضع والدراسة وعينتها، وبالإرتكاز إلى بجموعة أخرىن من المقاييس التي تم

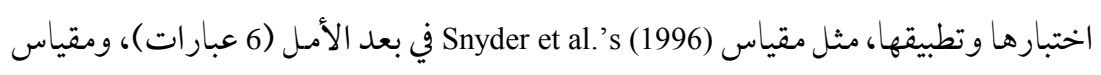


Scheier and Carver’s (1985) لبعد Wagnild and Young’s (1993) مستون الكفاءة الذاتية (7 عبارات)، ومقياس النهوض(7 عبارات)؛ ليكون عدد العبارات لكل الأبعاد (26) عبارة، بزيادة عبارتين عن مقياس Luthans لر أس المال النفسي. r- جودة حياة العمل: قام الباحث بتكوين مقياس جودة حياة العمل بالارتكاز إلى خبرته الشخصية بالتعليم الجامعي، والاستفادة من الأدبيات التي تناولت الموضوع، إضافة لمجموعة من المقاييس التي تم تقنينها، واختبارها وتطبيقها بالعديد من المجالات مثل مقياس Walton ومقياس . Sirgy et al (2001)، ومقياس Easton\&Van Laar (2013) المكون من ستة أبعاد، ومقياس . Newis et aller and المكون من 8 أبعاد، و مقياس (2001) الميس المكون من أربعة أبعاد، وتم الاستقرار علن خمسة أبعاد لتقيس هذا المتغير، وهي أجور أو حوافز عادلة ( 6 عبارات)، وتوفر فرص التنمية المهنية ( 7 عبارات)، والأمـان

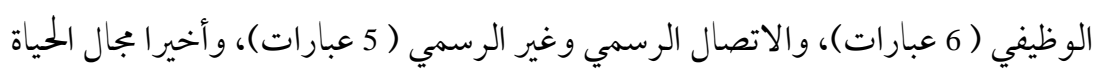
الكلي ( 6 عبار ات) بمجمل 30 عبارة للمقياس. r- مقياس الالتزام التنظيمي: تم إعداد مقياس الالتزام التنظيمي بالاستناد إلى الأدبيات، وبالاعتماد بشكل رئيس علن مقياس Meyer and Allen وطوره Meyer, Allen and وطنمي 1993 Smith العمل لميدان الدراسة.

ع- - الأساليب الإحصائية المستخدمة: اسـتنادا إلـئ أهـداف الدراسة ومضــامين فروضها تـم الاعتهاد علن عدد من الأساليب الإحصائية، وتم الاستعانة بحزمة البرامج الإحصائية SPSS التالية: 
• المتوســات الحسـابية والانحرافـات المعياريــة لاسـتخدامها فـي وصف

$$
\text { متغيرات الدراسة . }
$$

معامل الارتباط: لقياس الارتباط بين متغيرات الدراسة حول إجابات أفر اد العينة.

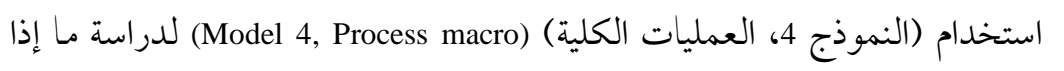
كانت جودة حياة العمل يتوسط العلاقة بين رأس الملال النفسي، والالتزام التنظيمي، وتم تقدير التأثير غير المباشر بـ \% bias-corrected (BC) 95 و فو فواصل الثقة .(Hayes, 2013 ; Preacher \& Hayes, 2004) (5000 confidence intervals (CI) تم استخدام اختبار Sobel للتحقق من دلالة التأثير غير المباشر للمتغيرات الوسيطة. تم الاعتماد علن الحدود الآتية في الحكم: المتوسط الحسابي (1- 2.33) يقابل التطبيق بدرجة ضعيفة، والمتوسط الحسابي من (2.34- 3.67) يقابل التطبيق بدرجة متوسطة،

$$
\text { والمتوسط الحسابي من (3.68- } 5 \text { ) يقابل التطبيق بدرجة مرتفعة. }
$$

$$
\text { صدق أدوات الدراسة }
$$

تم حساب الصدق من خلال طريقتين هما الصدق الظاهري: من خلال التأكد من أن الفقرات التي وردت يمكنها أن توفر البيانات المطلوبـة بدقة عالية، وجاء ذلك بمرحلتين: الأولى من فئن تمثلت بعرضها علن عدد مـن المحكمسين، وتم تعديل أداتي الدراسة بناء علن اقتراحاتهم، والثانية من خلال الاتساق الداخلي: بحساب قيم معاملات الارتباط بين درجات مفردات المقياس، ومجموع

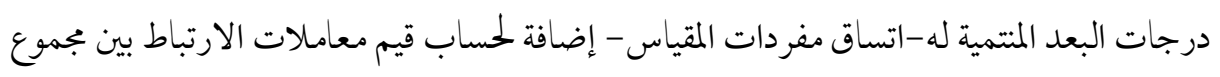
درجات كل محور من محاور المقياس والمجموع الكلن للدرجات -اتساق المحاور. 
Volume (1) No. (4) 2018

\begin{tabular}{|c|c|c|}
\hline معامل الارتباط & عدد الفقر ات & المحور \\
\hline $.682 * *$ & 26 & \\
\hline $.660 * *$ & 7 & الكفاءة الذاتية \\
\hline $.678 * *$ & 7 & 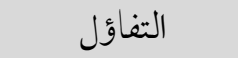 \\
\hline $.639 * *$ & 6 & \\
\hline $.631 * *$ & 6 & \\
\hline $.913 * *$ & 29 & جوم \\
\hline $.899 * *$ & 6 & الأجور والمكافئات \\
\hline $.921 * *$ & 7 & فرص التنمية المهنية \\
\hline $.901 * *$ & 6 & الأمـان ا \\
\hline $.820 * *$ & 5 & الاتصال \\
\hline $.886^{* *}$ & 5 & جودة الحياة الكلية \\
\hline $.863 * *$ & 14 & \\
\hline
\end{tabular}

من الجدول السابق يتضح أن جميع معاملات الارتباط بين مجموع درجات المقياس الأول، والمجموع الكلان للدرجات مرتفعاً ودال إحصائيًا، وبين مجموع درجات أبعاد المقياس الأول، ومجموعه مرتفعة أيضا ودالة، كما أن مجموع درجات المقياس الثاني والثالث، وهما جودة حياة العمل والالتزام التنظيمي مرتفعة ودالة إحصائيا مما يعد مؤشراً لارتباط محاور الاستبانة بالهدف الذي تسعى دمئ 
/ / حممود سيد علي أبو سيف

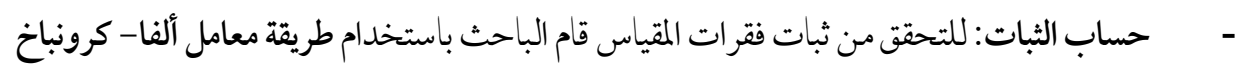
جدول (r) يبين قيم معامل ألفا كرونباخ لمقايس الدراسة

\begin{tabular}{|c|c|}
\hline ألفا كرونباخ & البعد \\
\hline .954 & رأس المال النفسي \\
\hline .955 & الكفاءة الذاتية \\
\hline .955 & التفاؤل \\
\hline .955 & الأمـل \\
\hline .955 & النهوض \\
\hline .947 & جودة حياة العمل \\
\hline .947 & الأجور والمكافئات \\
\hline .948 & فرص التنمية المهنية \\
\hline .948 & الأمان الوظيفي \\
\hline .950 & الاتصال \\
\hline .949 & جودة الحياة الكلية \\
\hline .955 & الالتزام التنظيمي \\
\hline
\end{tabular}

يتضح من الجحدول(4) قيمة معامل ألفا لمقياس رأس المال النفسي قد بلغت (954.)، كما بلغت قيمة معامل ألفا لمقياس جودة حياة العمل (947.)، ولإلتزام التنظيمي(955.) وهي معاملات مرتفعة، وتقترب من الو احد الصحيح، مما يعد مؤشراً علن ثبات مقاييس الدراسة، وصلاحيتهم للاستخدام. 
Dr. Abosaif, Mahmoud Sayed Ali

Volume (1) No. (4) 2018

تحليل نتائج الدراسة الميدانية

في هذا الجزء سوف يقوم الباحث بتحليل محاور الاستبانة بغية الإجابة على أسئلة الدراسة،

$$
\text { وقد جاءت نتائج الدراسة: }
$$

1 -مستوى رأس المال النفسي وأبعاده لدى أعضاء هيئة التدريس بكلية التربية في جامعة الطائف، وقد

$$
\text { تم استخدام المتوسطات، والانحر افات المعيارية لتوضيح ذلك في الجمدول رقم(5) }
$$$$
\text { جدول (0) يبين المتوسطات الحسابية والانحرافات المعيارية لمستوى رأس المال النفسي رجي }
$$

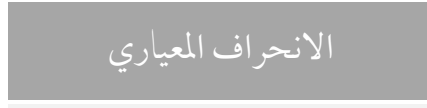

.51

.58

.57

.53

.52
المتو سط الخسابي

4.06

4.00

4.02

4.05

4.03
الكفاءة الذاتية

$$
\text { التفاؤل }
$$

الأمل - (- المل

\section{النهوض}

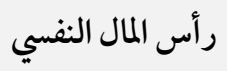

يتضح من الجمدول السابق أن أعضاء هيئة التدريس بكلية التربية جامعة الطائف يتمتعــون

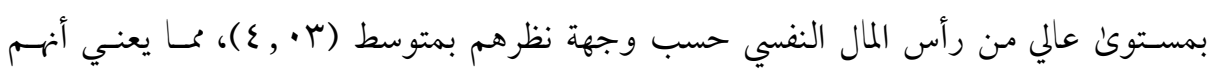
يمتلكـون الصفات الشخصية التي تؤهلهم للتـأثير في محيطهم الأكـاديمي حسب استجابتهم علن فقرات الاستبانة، والـــي يستـند إلـئ اعتقـادهم بالقـــرات، والإمكانيـات الموجـودة عندهم. ويرجع السبب إلى مستوكا خبراتهم العلمية والتربوية التي ولدت لديهم الاعتقادات اللازمة في كيفية التصدي للمشكلات التي تواجهرم في ميدان عملهم بأفضل الطرق التربوية المناسبة. ويمكن ترتيب أبعاد رأس الملال النفسي طبقا للأعلى تحققا لدئ أعضاء هيئة التدريس على النحو التالي: r-النتائج المتعلقة بمستوى جودة حياة العمل بكلية التربية جامعة الطائف من وجهة نظر أعضاء هيئة التدريس، والجدول يبين ذلك.

http://dx.doi.org/10.29009/ijres.1.4.4 
جدول (6) ييين المتوسطات الحسابية والانحر افات المعيارية لمستوكل جودة حياة العمل بكلية التربية

\begin{tabular}{|c|c|c|c|}
\hline 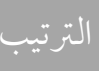 & الانحر اف المعياري & المتو سط الحسابي & 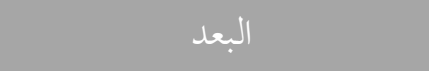 \\
\hline 1 & .78 & 3.42 & أجور وحو افز عادلة \\
\hline 2 & .82 & 3.39 & التنمية المهنية \\
\hline 4 & .83 & 3.35 & الأمـان الوظيفي \\
\hline 5 & .83 & 3.34 & جودة الاتصال الداخلي والخـارجي \\
\hline \multirow[t]{2}{*}{3} & .78 & 3.38 & جودة الحياة العامة \\
\hline & .79 & 3.38 & المجموع \\
\hline
\end{tabular}

يتضح من الجدول السابق أن مستوى جودة حياة العمل السائد بكلية التربية جامعة الطائف جاء

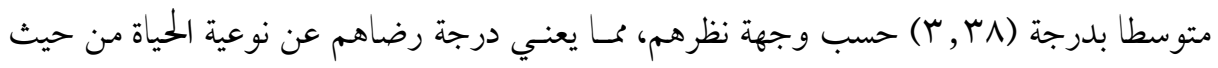
الأجور، ومستوكن التنيمية المهنية وشعورهم بالأمان الوظيفي متوسط، ويمكن تبرير ذلك بإحساس أعضاء هيئة التدريس بأنهم فئة مميزة اجتماعيا من حيث قدراتهم العلمية والبحثية إلا أن المردود المادي، والمعنوي لا يوازي هذا الشعور، تتفق هذه النتيجة مع دراسة Pani (2015) التي أظهرت أن مستون جودة حياة العمل، والمتغيرات الفرعية جاء بدرجة متوسطة من وجهة نظر أعضاء هيئة التدريس، فيما تختلف مع دراسة (2011) . Bharathi et al ؛ما يدلل علن أن شعور أعضاء هيئة التدريس من بيئات عالمية خختلفة يتراوح بين المتو سط والضعيف. يمكن ترتيب الأبعاد الفرعية حسب التالي: r-مستوى الالتزام التنيمي لدى أعضاء هيئة التدريس بكلية التربية جامعة الطائف: يمكن توضيح مستوى الالتزام التنظيمي بأبعاده الثلاثة من خلال الجلدول التالي: 
Dr. Abosaif, Mahmoud Sayed Ali

Volume (1) No. (4) 2018

\begin{tabular}{|c|c|c|}
\hline الانحر اف المياري & المتو سط الحـ & الفقرة \\
\hline .823 & 3.51 & الالتزام الاستمراري \\
\hline .872 & 3.54 & الالتزام المعياري \\
\hline .706 & 3.54 & الالتزام العاطفي \\
\hline
\end{tabular}

يبين الجدول رقم (7) أن مستوئ الالتزام التنظيمي لدىن أعضاء هيئة التدريس بكلية التربية جامعة الطائف متوسطا، حيث بلغ المتوسط الحسابي للإجابات عن هذا المتغير (3.54) بانحراف معياري (70.)، وهي نسبة تحقق متوسطة، حيث تتفق هذه النتيجة مع دراسة خضير (1996)، وجاء مستون الالتزام العاطفي في المستوئ الأول بمتوسط (3.54)، والالتزام المستمر في الترتيب الأخير بمتوسط(3.51).

التحقق من فروض الدراسة واختبار العلاقة الارتباطية بين متغيرات الدراسة، ومستوى الدور المباشر وغير المباشر للمتغير المستقل على المتغير التابع. لإجراء هذه المرحلة هناك العديد من النهاذج والاختبارات التي يمكنها اختبار الدور الوسيط، إلا أن أفضلها لتحقيق أهداف الدراسة الحالية هما نموذج (1986) Baron and Kenny's

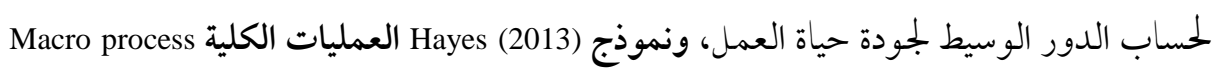
الذي تم الاعتماد عليه بشكل رئيس، وفيما يلي عرض لهذه الخطوات: الخطوة 1: تطبيق اختبار الانحدار لمعرفة العلاقة بين المتغير الوسيط، والمتغير المستقل للتأكد من أن المتغير المستقل هو مؤشر هام للوسيط. إذا لم يكن الوسيط مرتبطا بالمتغير المستقل، فلا يمكن أن يتوسط أي شيء، وإذا تحقق الارتباط نكمل. الخطوة 2: تطبيق اختبار الانحدار لمعرفة العلاقة بين المتغير التابع مع المتغير المستقل للتأكد من أن المتغير المستقل هو مؤشر هام للمتغير التابع إذا كانت دالة نكمل الاختبار. الخطوه 3:

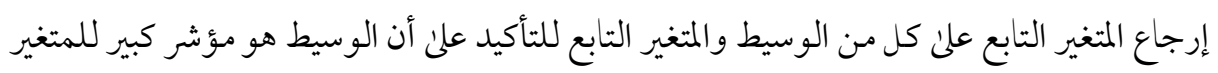
التابع، وقد تم الآن تقليل المتغير المستقل الهام سابقا في الخطوة رقم 1 بشكل كبير، إن لمريكن غير هام. 
ولتحقيق الخطوة الثالثة يبين الشكل (1) مسار تأثير المتغير المستقل (X) علن المتغير التابع(Y) ، ويعرف

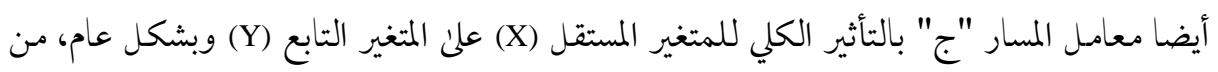

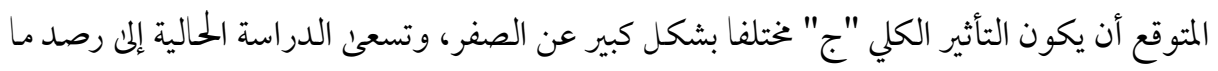
إذا كان تأثير المتغير المستقل (X) علن المتغير التابع (Y) ناتج عن وجود عامل آخر، وهو ما يطلق عليه متغير الوسيط.

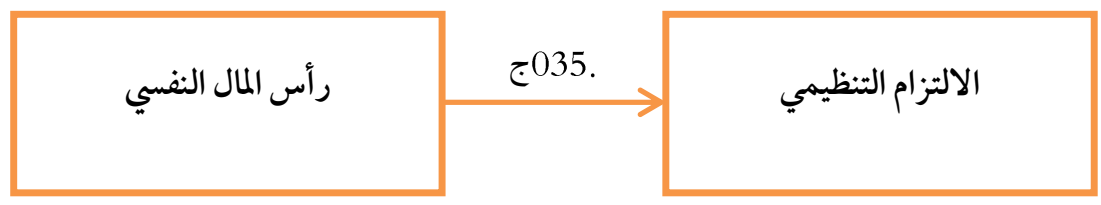

$$
\text { شكل رقم (1) يتناول العلاقة المباشرة بين المتغير المستقل والمتغير التابع }
$$

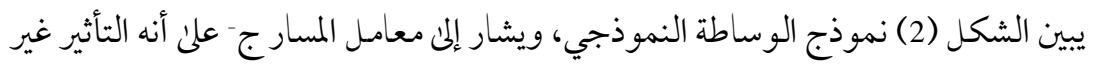

المباشر للمتغير المستقل (X) علن المتغير التابع(Y)، ويعرف أيضا بتأثير المتغير الوسيط (M) علن المتغير

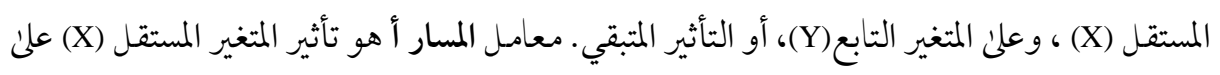

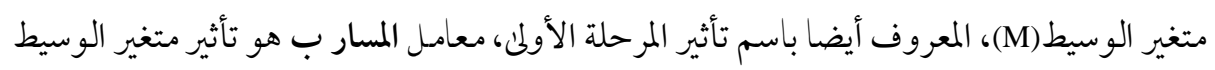
(M)

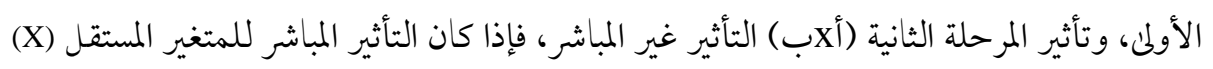
علن المتغير التابع (Y) بعد إضافة متغير الوسيط (M) معنوي (بمعنى أن معامل المسار ج كبير)، فإنه يعرف باسم الوساطة الكاملة. 
Volume (1) No. (4) 2018

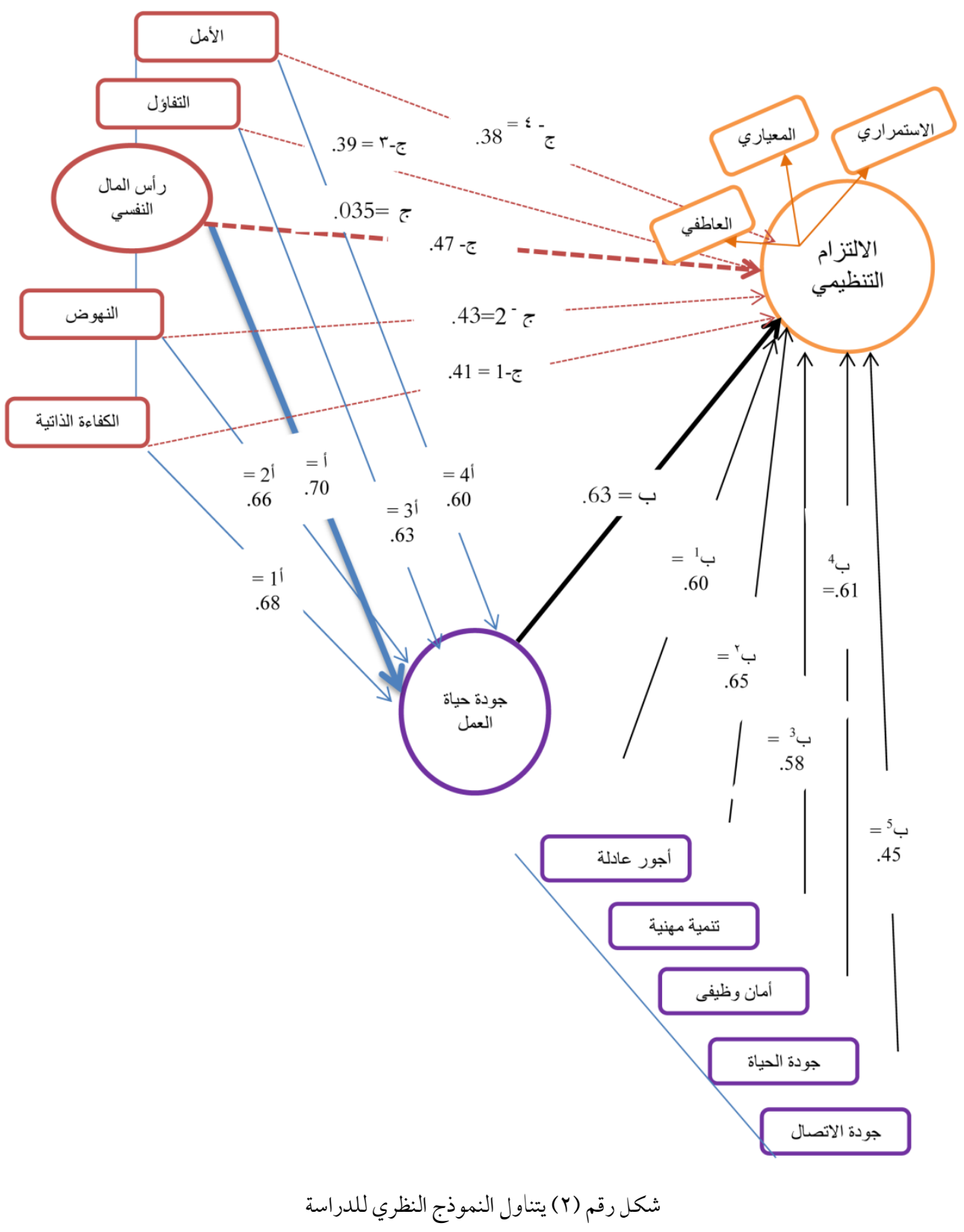

http://dx.doi.org/10.29009/jires.1.4.4 
/ محمود سيد علي أبو سيف

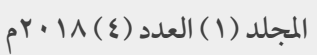

لدراسة ما إذا كان جودة حياة العمل تتوسط العلاقة بين رأس المال النفسي، والالتزام (Model 4, التنيمي، أجريت تحليلات الوساطة باستخدام (النموذج 4، الماكرو بروسيسي) PROCESS macro) وفو اصل الثقة (Hayes, 2013; Preacher \& Hayes, 2004) (5000 confidence intervals (CI). الخطوة 1: تطبيق اختبار الانحدار لمعرفة علاقة وأثر رأس المال النفسي علن جودة حياة العمل : يمكن عرض هذا التأثير من خلال الجدول التالي: جدول (8) المسار (أ) أثر رأس المال النفسي علن جودة حياة العمل

\begin{tabular}{|c|c|c|c|c|c|c|}
\hline \multicolumn{7}{|c|}{ ملخص الثموذج } \\
\hline $\mathbf{P}$ & df2 & df1 & $\mathbf{F}$ & MSE & R-sq & $\mathbf{R}$ \\
\hline .0002 & 48.0000 & 1.0000 & 16.4778 & 4952 & .2225 & .47 \\
\hline
\end{tabular}

\section{ULCI الحد الحد الأدنى LLCI}

لفاصل الثقة

لفاصل الثقة

1.0576 p

$\mathbf{T}$

Se

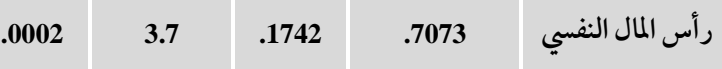

$$
\begin{aligned}
& \text { اتضح من الجدول أن المسار (أ) كان دالا حيث إن : }
\end{aligned}
$$

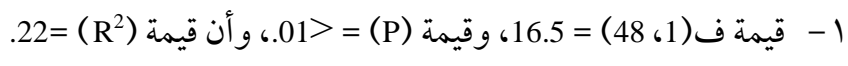

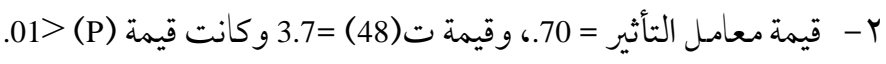

مما يدل علن أن المسار (أ) دال من خلال التأثير الموجب، والمباشر لرأس المال النفسي على مستوى جودة حياة العمل لدنى أعضاء هيئة التدريس بكلية التربية بجامعة الطائف، مما يسمح باستمرار اختبار الدور الوسيط لجودة حياة العمل. من خلال ما سبق تقبل الفرضية الأولن والتي

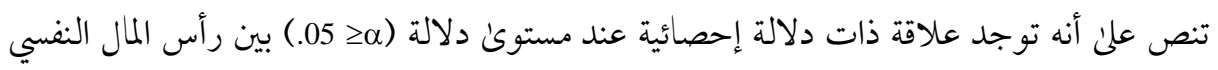


Dr. Abosaif, Mahmoud Sayed Ali

Volume (1) No. (4) 2018

وجودة حياة العمل لدى أعضاء هيئة التدريس بكلية التربية في جامعة الطائف. وتتفق هذه النتيجة مع

دراسة(2012) Mortazavi, Yazdi, Amini و موع دراسة (2011) Nguyen \&Nguyen الخطوة الثانية: التأثير الثنائي لرأس المال النفسي وجودة حياة العمل على مستوى الالتزام التنظيمي تمثل هذه الخطوة اختبار للمسارين (ب) و(ج) ويمكن توضيحها من خلال الجدول التالي: جدول (9) ييين التأثير الثنائي لر أس المال النفسي وجودة حياة العمل علن مستوى الالتزام التنظيمي

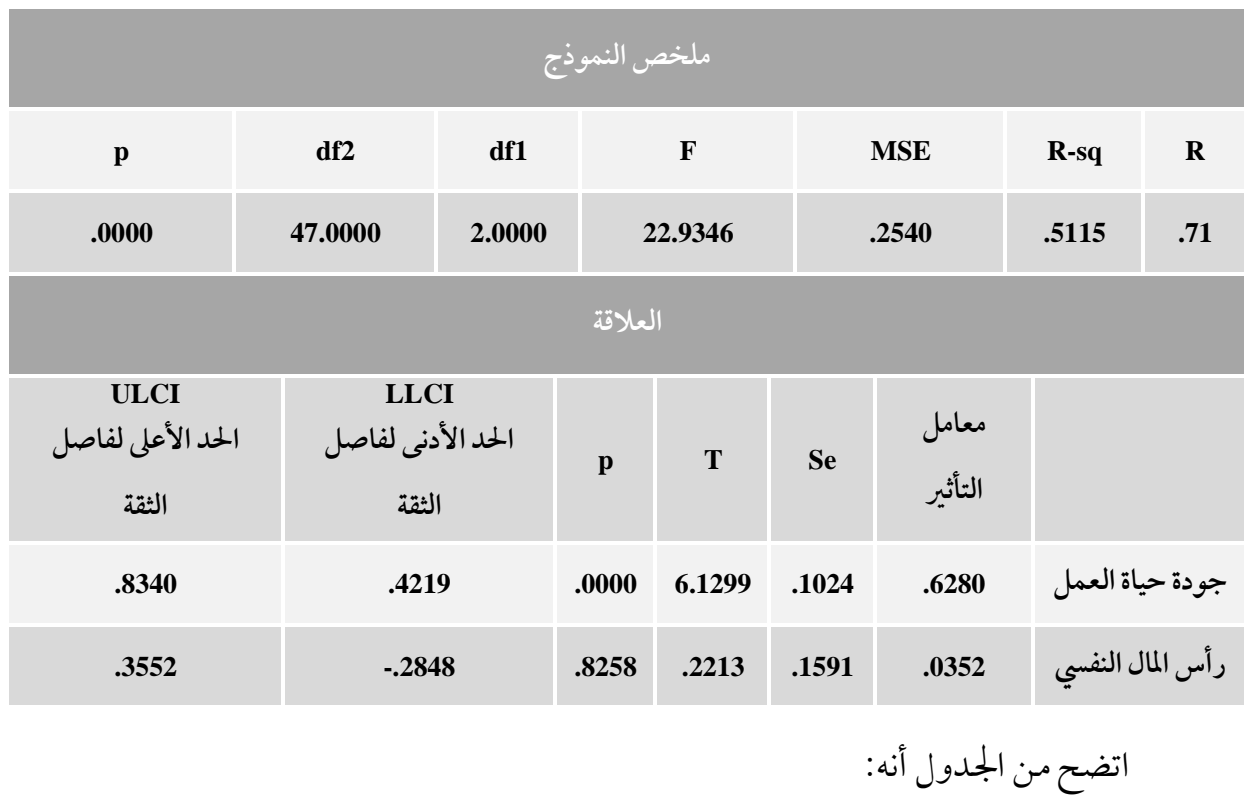

1- يوجد تأثير ثنائي كلي لرأس المال الفكري وجودة حياة العمل علن التبؤ بمستوى الالتزام

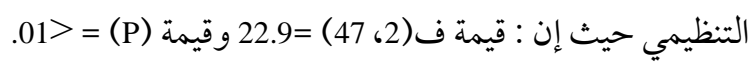

ץ- فيما يتعلق بالمسار(ب) وهو درجة تأثير جودة حياة العمل على مستوى الالتزام التنظيمي،

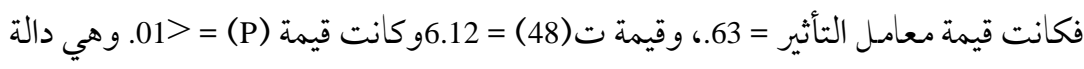

$$
\text { إحصائيا. }
$$

بناء على هذا يقبل الفرض الثاني بوجود علاقة وتأثير طردي مباشر لجودة حياة العمل على مستوى الالتزام التنظيمي. 
r- أما المسار (ج) وهو درجة التأثير المباشر لرأس المال النفسي علن مستوكن الالتزام التنظيمي،

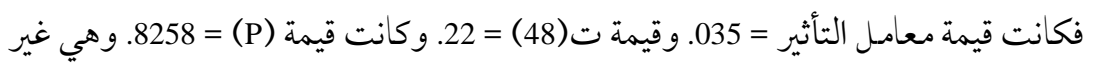

$$
\text { دالة إحصائيا. }
$$

بناء على هذا يرفض الفرض الثالث بوجود علاقة، وتأثير طردي مباشر لرأس المال النفسي على

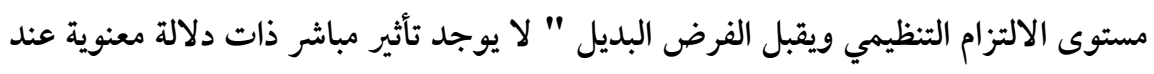

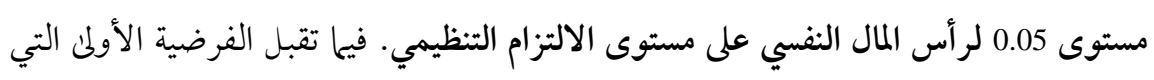

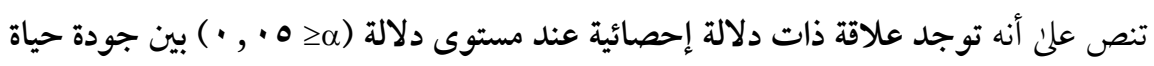

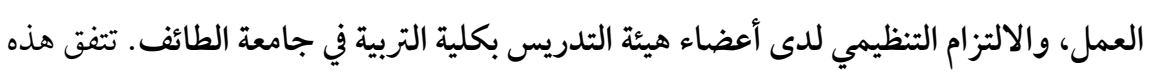

النتيجة مع دراسة Farid; Izadi; Ismail\& Alipour (2014)، ودراسة البلبيسي (2012 ).

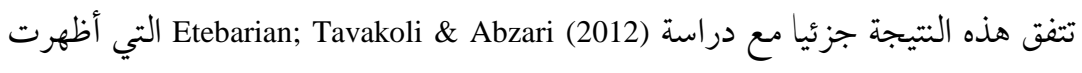
نتائج تحليل الانحدار أن متغيرين فرعيين فقط لرأس المال النفسي، وهما الأمل والنهوض دئل يمكنها

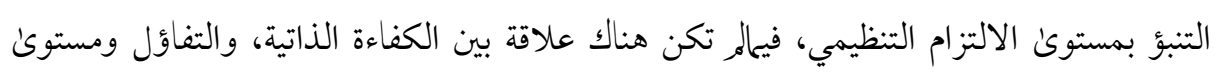

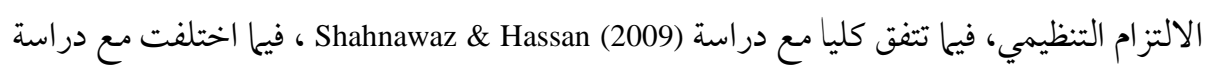
Zhong (2007).

الخطوة الثالثة : دور المغير الوسيط في العلاقة بين المتغير المستقل والمتغير التابع

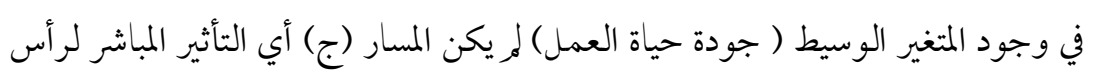

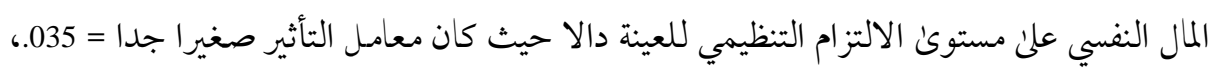
فيا كانت قيمة ت(48) =0.22، وقيمة P= 0.82 وهي قيمة غير دالة إحصائيا لمستوى تأثير المتغير

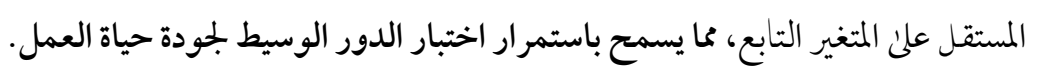

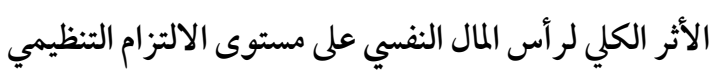


جدول (10) ييين نتائج تحليل الوساطة باستخدام طريقة الماكرو بروسيس لمعرفة الأثر الكلي لرأس المال النفسي علن. الالتزام التنظيمي

\begin{tabular}{|c|c|c|c|c|c|c|c|}
\hline \multicolumn{8}{|c|}{ ملخصى الثموذج } \\
\hline P & df2 & df1 & & قيمة فـ & MSE & التحديد معامل & $\begin{array}{c}\text { معامل الارتباط } \\
\text { R }\end{array}$ \\
\hline . 0059 & 48.0000 & 1.0000 & & 3.3046 & .4439 & . 1278 & .35 \\
\hline \multicolumn{8}{|c|}{ العلاقة } \\
\hline غاصل & الحد الأعال & $\begin{array}{c}\text { LLCI } \\
\text { الحد الأدنى لفاصل }\end{array}$ & $\mathrm{p}$ & ت & $\mathrm{Se}$ & معامل التأثير & \\
\hline & 38 & .1449 & . 0059 & 2.881 & 166 & . 4793 & رأس المال \\
\hline
\end{tabular}

يتضح من الجدول السابق أن قيمة معامل التأثير لرأس المال النفسي قد ارتفعت من ( 03.)، وهي التأثير المباشر لرأس المال النفسي علن مستوى الالتزام التنظيمي إلى (47. )، وهي قيمة التأثير الكلي في وجود متغيرات أخرىن، وهذا يوضح قيمة التأثير غير المباشر لجودة حياة العمل في العلاقة بين المتغير المستق والتابع، ويمكن عمل مقارنة لكل أشكال التأثير الموجودة من خلال الجلدول التالي:

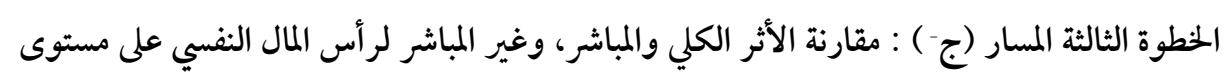
الالتزام التنظيمي: الدور الوسيط لجودة حياة العمل في العلاقة بين المتغيرين

إن الاختبارات النظرية العادية للآثار غير المباشرة تحسب الأخطاء المعيارية باستخدام طريقة الدلتا التي تفترض أن تقديرات التأثير غير المباشر توزع بشكل اعتيادي، فيما تعتمد طريقة المعاينة

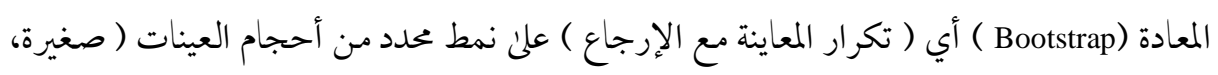


متوسطة، وكبيرة ) علئ القيم الاحتمالية لمستويات الدلالة المتحققة، وذلك في ضوء نمط البيانات المستخدمة فييا اذا كانت حقيقية ( باتجاه تحقق الشكل البيضوي للتوزيع الطبيعي متعدد المتغيرات ). حيث تم استخدام طريقة المعاينة المعادة (Bootstrap ) من (5000) عينة باستخدام النموذج ع في الماكرو بروسيس ل هايز (2013) للتحقيق في آثار الوساطة؛ لأنه في كثير من الحالات لا يمكن الوثوق في اختبار z و قيم p لهذه التأثيرات غير المباشرة؛ ولذلك، فمن المستحسن أن يتم استخدام فو اصل الثقة confidence intervals. ويمكن تناول ذلك من خلال: جدول (11) يبين نتائج تحليل لطريقة العمليات الكلية لمعرفة الدور غير المباشر لرأس المال النفسي علن الالتزام التنظيمي

\begin{tabular}{|c|c|c|c|c|c|c|}
\hline $\begin{array}{c}\text { ULCI } \\
\text { الحد الأعلى لفاصل الثقة }\end{array}$ & $\begin{array}{c}\text { LLCI } \\
\text { الحد الأدنى لفاصل الثقة }\end{array}$ & $\mathbf{P}$ & $\mathrm{T}$ & $\mathrm{Se}$ & التأثير & \\
\hline .8427 & .1160 & .0108 & 2.652 & .1807. & .4793 & التأثر الكلي \\
\hline .3470 & -.2766 & .8213 & .2271 & .1550 & .0352 & التأثير المباشر \\
\hline .7287 & 2390 & .0017 & & .1418. & .4441 & المباشر : الدور \\
\hline
\end{tabular}

يتضح من الجمدول أن جودة حياة العمل تتوسط العلاقة بين رأس المال النفسي، ومستوكن الالتزام التنظيمي من خلال:

ا-مستون التأثير غير المباشر لجمودة حياة العمل في علاقة رأس المال النفسي بمستوى الالتزام التنظيمي لدى أعضاء هيئة التدريس بكلية التربية بلغ (0.44)، والتي ساهمت في رفع مستوى تأثير رأس المال النفسي المباشر علن مستوى الالتزام التنظيمي من (035.) إلى (48.)، كما أن قيمة (ت) تغيرت من (2.7.) (2.022)، وتحول مستوكن الدلالة لقيمة (P) من غير الدالة 82.إلى 01. قيمة دالة إحصائيا. r-ككا يشير Hayes (2013) إلى مستون الدلالة يتم تحديده من فو اصل الثقة، فإذا كانت القيم الدنيا، و العليا بعيدة عن الصفر كان الدور الوسيط دالا، وبالنظر للجدول نجد أن قيمة LLCI الحد الأدنئ 
لفاصل الثقة = 2390، وقيمة ULCI الحد الأعلن لفاصل الثقة = 7287. وكلتا القيمتين بعيدة عن الصفر مما يدل علن دلالة الدور الوسيط.

يستتج الباحث مما سبق أن جودة حياة العمل تتوسط العلاقة بين رأس المال النفسي السائد لدى أعضاء هيئة التدريس بكلية التربية جامعة الطائف، ومستوى التزامهم التنظيمي.

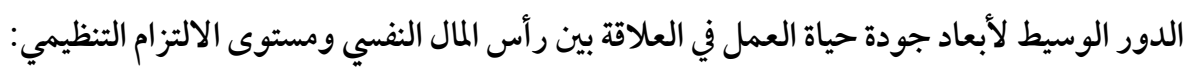
اتضح من بيانات جدول (24) أن جميع أبعاد جودة حياة العمل الخمسة تتوسط العلاقة بين

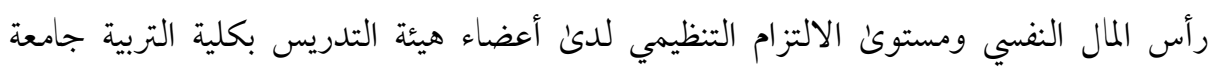
الطائف، يمكن تناول ذلك علن النحو التالي:

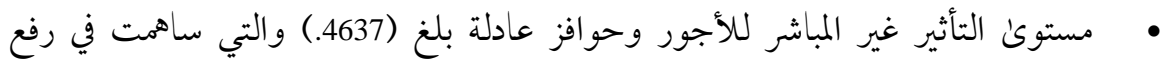

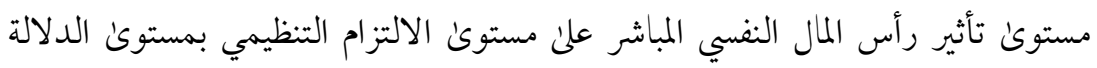

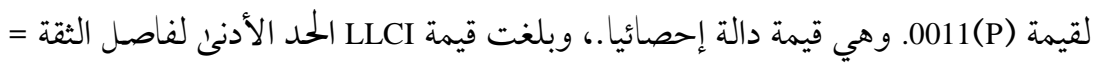

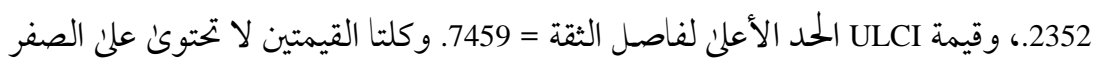

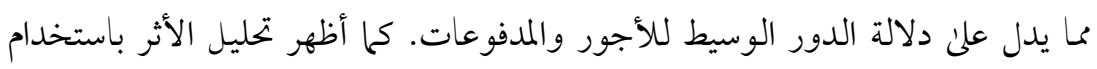

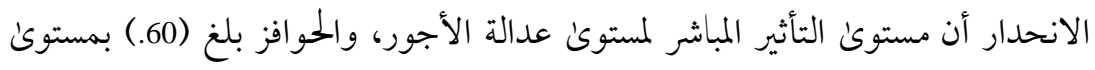

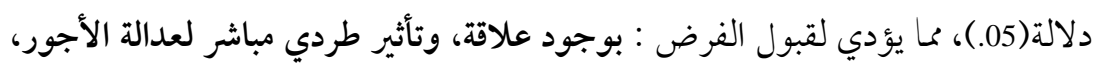
والحو افز على مستوى الالتزام التنظيمي لدى أعضاء هيئة التدريس بكلية التربية.

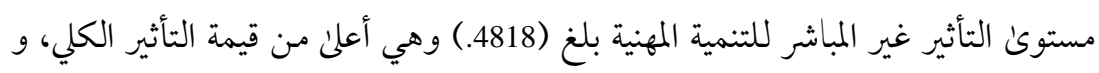

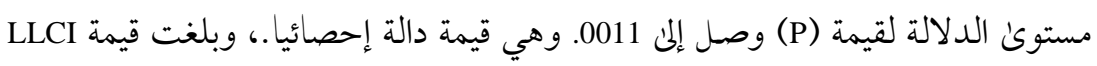

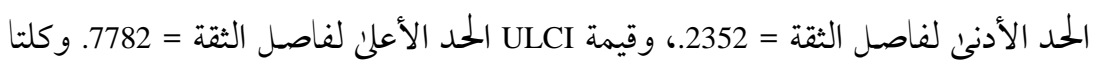

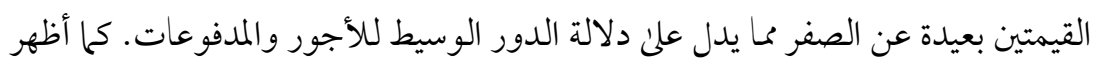

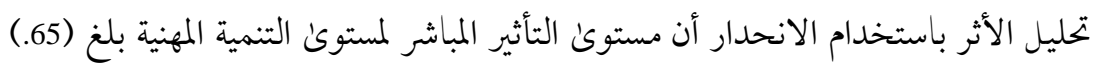

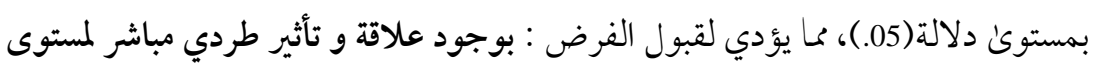


التنمية المهنية على مستوى الالتزام التنيمي لدى أعضاء هيئة التدريس بكلية التربية جامعة

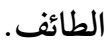

بلغ مستوى التأثير للدور الوسيط للأمان الوظيفي (4288.)، و مستوى الدلالة لقيمة (P) 002. وهي قيمة دالة إحصائيا،، وبلغت قيمة LLCI الحد الأدنى لفاصل الثقة = 2636.-6 وقيمة ULCI الحد الأعلى لفاصل الثقة = 3647. وكلتا القيمتين بعيدة عن الصفر مما يدل على دلالة الدور الوسيط للأجور والمدفوعات. كما أظهر تحليل الأثر باستخدام الانحدار أن مستوى التأثير المباشر لمستوى الأمان الوظيفي بلغ (58.) بمستون دلالة(05.)، مما يؤدي لقبول الفرض الفرعي : بوجود تأثير طردي مباشر للأمان الوظيفي على الالتزام التنيمي لدى أعضاء هيئة التدريس بكلية التربية جامعة الطائف. بلغ مستوك التأثير غير المباشر لجودة الحياة العامة (3973.)، بمستوكي الدلالة لقيمة (P).01. وهي قيمة دالة إحصائيا.، وبلغت قيمة LLCI الحد الأدنى لفاصل الثقة = 2244.-، وقيمة الحد الأعلى لفاصل الثقة = 3885. وكلتا القيمتين بعيدة عن الصفر. كما أظهر تحليل ULCI الأثر باستخدام الانحدار أن مستوى التأثير المباشر لمستون جودة الحياة العامة بلغ (61.)

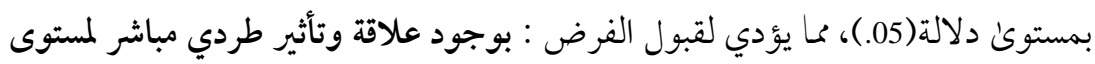
جودة الحياة العامة على مستوى الالنزام التنظيمي لدى أعضاء هيئة التدريس بكلية التربية

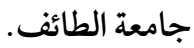
كما لعبت جودة الاتصال الداخلي والخارجي دور وسيطا بمستون تأثير (2916.) ومستون دلالة 015. وهي قيمة دالة إحصائيا.، وبلغت قيمة LLCI الحد الأدنى لفاصل الثقة = 1171.، وقيمة ULCI الحد الأعلان لفاصل الثقة = 5625. وكلتا القيمتين بعيدة عن الصفر. كما أظهر تحليل الأثر باستخدام الانحدار أن مستوىن التأثير المباشر لمستون جودة الاتصالات الداخلية والخارجية بلغ (45.) بمستون دلالة(05.)، مما يؤدي لقبول الفرض: بوجود 
Dr. Abosaif, Mahmoud Sayed Ali

Volume (1) No. (4) 2018

علاقة، وتأثير طردي مباشر لجودة الاتصالات الداخلية، والخارجية على مستوى الالتزام

\section{التنظيمي لدى أعضاء هيئة التدريس بكلية التربية.}

جدول (12) يبين نتائج تحليل لطريقة العمليات الكلية لمعرفة الدور الوسيط لأبعادة جودة حياة العمل في العلاقة بين

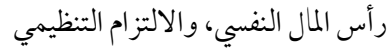

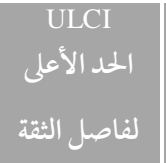

.3508

.7459

.2352

.0011

.9258

.0937

$-.3196$

$\begin{array}{r}.2913 \\ \hline .7782 \\ \hline\end{array}$

.3647

$-.2636$

.7478

0.3234

.1562

.1400

.4288

.0156

التأثير المباشر

الأجور

.1425

.4637

التأثير غير المباشر:

والحو افز

الدور الوسيط

العادلة - ماد

.6951

.2081

.0022

$-.025$

$$
\text { التأثير المباشر }
$$

.4818

$$
\text { التأثير غير المباشر: }
$$$$
\text { الدور الوسيط }
$$

التنمية

المهنية

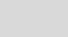

.0505

التأثير المباشر

الأمان

التأثير غير المباشر:

\begin{tabular}{|c|c|c|c|c|c|c|c|}
\hline .3885 & -.2244 & .5926 & .5388 & .1523 & .0821 & التأثير المباشر & جودة \\
\hline .6311 & .1984 & .0039 & & .1377 & .3973 & التأثير غير المباشر: & والداخلي \\
\hline .5255 & -.1500 & .2691 & 1.1183 & .1679 & .1878 & التأثير المباشر & \\
\hline .5625 & .1171 & .0150 & & .1199 & .2916 & التأثير غير المباشر: & العامة \\
\hline
\end{tabular}

الدور الوسيط 


\section{/ محمود سيد علي أبو سيف

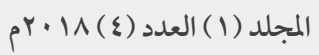

فيها يخص الدور الوسيط لجودة حياة العمل بين أبعاد رأس المال النفسي (الكفاءة الذاتية، و النهوض، والتفاؤل، والأمل)، ومستوئ الالتزام التنظيمي:

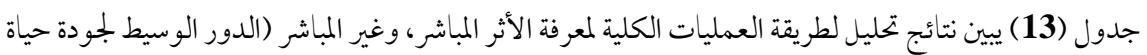

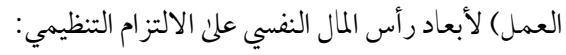

\begin{tabular}{|c|c|c|c|c|c|c|}
\hline $\begin{array}{c}\text { ULCI } \\
\text { الحد الأعلى لفاصل الثقة }\end{array}$ & $\begin{array}{c}\text { LLCI } \\
\text { الحد الأدنى لفاصل الثقة }\end{array}$ & P & $\mathrm{T}$ & $\mathrm{SE}$ & التأثير & \\
\hline \multicolumn{7}{|c|}{ الكفاءة الذاتية } \\
\hline .8618 & .1213 & .010 & 2.6695 & .1841 & .4916 & التأثر الكلي \\
\hline .3837 & -.2414 & .649 & .4578 & .1554 & .0711 & التأثير المباشر \\
\hline .6940 & .1840 & .003 & & .1419 & .4205 & التأثير غير المباشر \\
\hline \multicolumn{7}{|c|}{ التفاؤل } \\
\hline .7859 & .1397 & .005 & 2.8798 & .1607 & .4628 & التأثر الكلي \\
\hline .3514 & -.2087 & .61 & .5125 & .1392 & .0713 & التأثير المباشر \\
\hline .6529 & .1963 & .001 & & .1255 & .3915 & التأثير غير المباشر: \\
\hline \multicolumn{7}{|c|}{ الأمل } \\
\hline .7416 & .0621 & .02 & 2.3779 & .1690 & .4019 & التأثر الكلي \\
\hline .3041 & -.2597 & .87 & .1585 & .1401 & .0222 & التأثير المباشر \\
\hline .6000 & .1699 & .003 & & .1303 & .3796 & التأثير غير المباشر: \\
\hline \multicolumn{7}{|c|}{ النهوض } \\
\hline .7589 & .0329 & .03 & 2.1930 & .1805 & .3959. & التأثر الكلي \\
\hline .2656 & $-\mathbf{3 3 8 0}$ & .81 & -.2412 & .1500 & -.0362 & التأثير المباشر \\
\hline .6905 & .2065 & .002 & & .1417 & .4321 & التأثير غير المباشر \\
\hline
\end{tabular}


يتبين من الجدول(25) دلالة الدور الوسيط لجودة حياة العمل في مستون تأثير أبعاد رأس المال النفسي علئ مستون الالتزام التنظيمي لدى أعضاء هيئة التدريس بكلية التربية جامعة الطائف، ويمكن تفسير ذلك فيما يلي: بلغ مستوى التأثير غير المباشر لجودة حياة العمل في علاقة الكفاءة الذاتية بمستون الالتزام التنظيمي (0.42) والتي ساهمت في رفع مستوى التأثير المباشر للكفاءة الذاتية لأعضاء هيئة التدريس علن مستوى الالنزام التنظيمي من ( 07.) إلى ( 50.)، كما أن قيمة (ت) تغيرت من (45.) إلى (2.6)، وتحول مستوى الدلالة لقيمة (P) من غير الدالة 64.إلى 01.، وهي قيمة دالة إحصائيا، كما أن قيمة الحد الأدنى لفاصل الثقة = 1840.، وقيمة الحد الأعلن لفاصل الثقة = 6940،، وكلتا القيمتين بعيدة عن الصفر مما يدل علنى دلالة الدور الوسيط. بناء علئ هذا يرفض الفرض الفرعي بوجود علاقة وتأثير طردي مباشر للكفاءة الذاتية علنم مستوى الالتزام التنظيمي، ويقبل الفرض البديل " عدم وجود تأثير مباشر ذات دلالة معنوية عند مستوكن 0.05، للكفاءة الذاتية علن مستوئ الالتزام التنظيمي". كحا تبين من تحليل الإنحدار لمستوى تأثير بعد الكفاءة الذاتية على مستوىن جودة حياة العمل، وجود تأثير طردي مباشر بدرجة (68.)، ومن ثم يتم قبول الفرض " بوجود تأثير مباشر ذات دلالة معنوية عند مستوى 0.05، للكفاءة الذاتية على

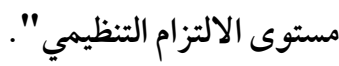
دلالة التأثير غير المباشر في علاقة التفاؤل بالالتزام التنظيمي حيث بلغ (3915.)، وكان مستوكي الدلالة لقيمة (P) دالا في وجود المتغير الوسيط بدرجة (005.) كما كانت كلتا قمتي فو اصل الثقة الدنيا، والعليا بعدة عن الصفر. بناء علن هذا يرفض الفرض الفرعي بوجود علاقة، وتأثير طردي مباشر للتفاؤل علن مستوكئ الالتزام التنظيمي، ويقبل الفرض البديل " عدم وجود تأثير مباشر ذات دلالة معنوية عند مستوى 0.05، للتفاؤل علئ مستوى الالتزام التنظيمي. كما تبين من تحليل الإنحدار لمستوئ تأثير بعد التفاؤل علن مستوئ جودة حياة العمل، وجود تأثير طردي 
مباشر بدرجة (63.)، ومن ثم يتم قبول الفرض " بوجود تأثير مباشر ذات دلالة معنوية عند مستوى 0.05، للتفاؤل على مستوى الالتزام التنظيمي". مستوئ التأثير غير المباشر لجودة حياة العمل في علاقة مستوئ الأمل السائد لدئ أعضاء هيئة التدريس بمستوى الالتزام التنظيمي بلغ (38.)، والتي ساهمت في رفع مستون التأثير

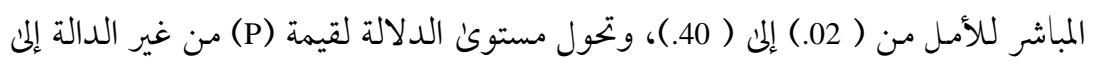
02.، وهي قيمة دالة إحصائيا، كما أن قيمة الحد الأدنى لفاصل الثقة = 1699.، وقيمة الحد الأعلان لفاصل الثقة = 6000.، وكلتا القيمتين بعيدة عن الصفر مما يدل علن دلالة الدور الوسيط. بناء علن هذا يرفض الفرض الثالث بوجود وعلاقة، وتأثير طردي مباشر للأمل على مستوي الالتزام التنظيمي ويقبل الفرض البديل "عدم وجود تأثير مباشر ذات دلالة

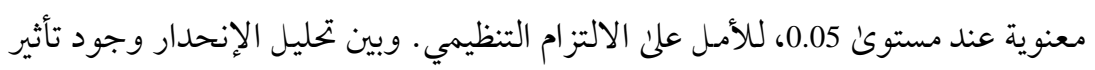
طردي مباشر بدرجة (60.)، ومن ثم يتم قبول الفرض " بوجود تأثير مباشر ذات دلالة

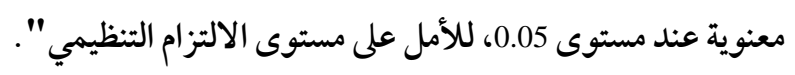
مستوى التأثير غير المباشر لجودة حياة العمل في علاقة النهوض بمستوئ الالتزام التنظيمي

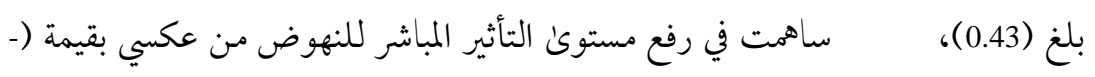
04.) إلى طردي بقيمة ( 4.)، وقيمة (ت) تغيرت من (24.-) إلى (2.4)، وتحول مستوني الدلالة لقيمة (P) من غير الدالة (81.)إلى (03.)، وهي قيمة دالة إحصائيا، كما أن قيمة

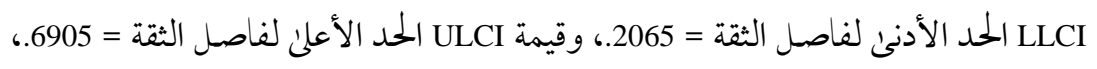
وكلتا القيمتين بعيدة عن الصفر مما يدل علن دلالة الدور الوسيط. بناء علن هذا يرفض

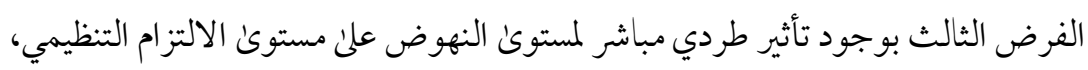
ويقبل الفرض البديل " وجود تأثير عكسي ضعيف للنهوض علن مستون الالتزام التنظيمي. كما تبين من تحليل الإنحدار وجود تأثير طردي مباشر بدرجة (66.)، وتم قبول 
الفرض " بوجود تأثير مباشر ذات دلالة معنوية عند مستوى 0.05 للكفاءة الذاتية على مستوى الالتزام التنظيمي".

\section{خلاصة البحث}

توصلت الدراسة لمجموعة من النتائج والتوصيات يمكن تناولها فيا يلي: أولا: نتائج الدراسة: خلصت الدراسة لمجموعة من النتائج يمكن توضيحها في النقاط التالية: النتائج المتعلقة بأسئلة الدراسة:

ا - مستون رأس المال النفسي لدنا أعضاء هيئة التدريس بكلية التربية جامعة الطائف جاء مرتفعا بمتوسط (4.03) من وجهة نظرهم، وكانت متوسط الاستجابة على أبعاد رأس المال النفسي علن الترتيب هي الكفاءة الذاتية بمتوسط 4.06، والنهوض بمتوسط 4.05، والأمـل بمتوسط (4.02)، والتفاؤل بمتوسط (4.00) وكلها درجات عالية. r- المتوسط العام لمستوكن جودة حياة العمل جاء متوسطا بدرجة (3.38)، وحصلت الأجور، والمكافآت علن أعلى درجة (3.42) فيما حصل مستوئ جودة الاتصال الداخلي والخارجي علن متوسط (3.34) في الترتيب الأخير من وجهة نظر أعضاء هيئة التدريس.

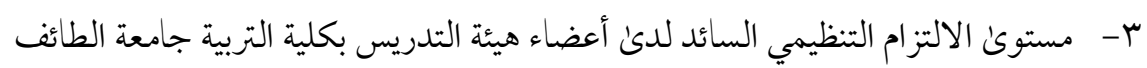
متوسطا، وكان المتوسط الحسابي (3.54) وكانت أعلى درجات الالتز ام التنظيمي لمستوى الالتزام العاطفي بمتوسط حسابي (3.58)، وأدناها لمستوى الالتزام المستمر، أو المستديم

$$
\text { أ- النتائج المتعلقة بفروض حسابي (3.51). }
$$

ع- قبول الفرض الأول بوجود علاقة بين رأس المال النفسي بمستون شعور عضو هيئة

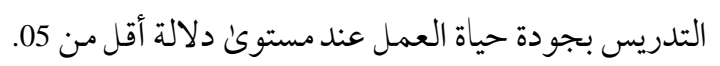

ه- قبول الفرض الثاني بوجود علاقة بين مستوئ جودة حياة العمل السائد بكلية التربية

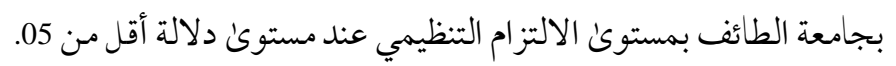


1- رفض الفرض الثالث بوجود علاقة بين رأس المال النفسي، ومستوئ الالتزام التظظيمي

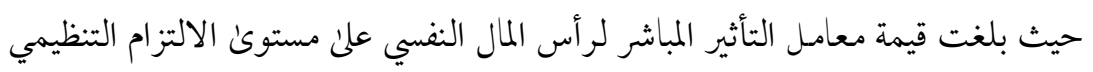

$$
\text { (03. ) بمستوى دلالة (82) }
$$

V- رفض الفرض الرابع بعدم توسط جودة حياة العمل للعلاقة بين رأس المال النفسي،

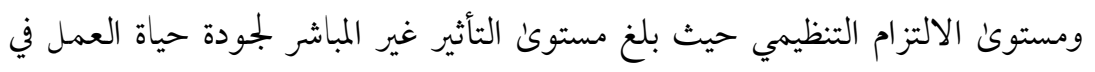

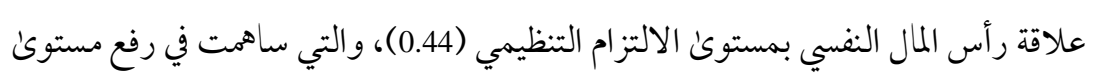

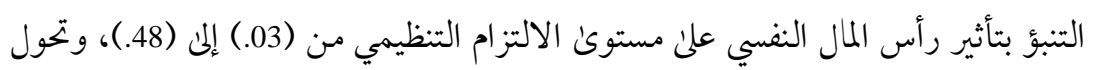

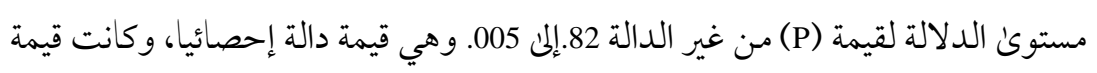

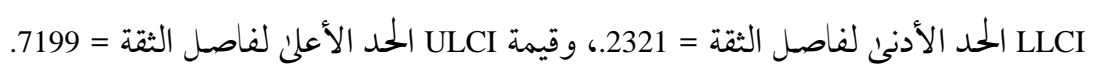
و كلتا القيمتين لا تحتوىن علن الصفر مما يدل علن دلالة الدور الوسيط.

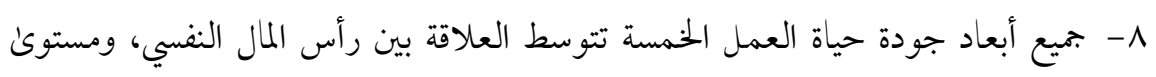
الالتزام التنظيمي لدئ أعضاء هيئة التدريس بكلية التربية جامعة الطائف:

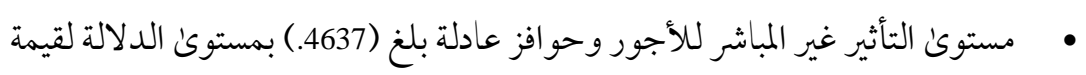
0011(P)

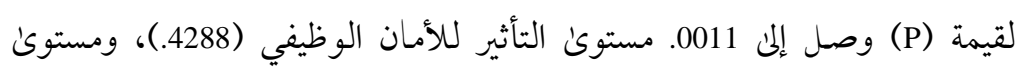

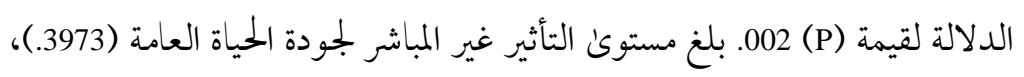

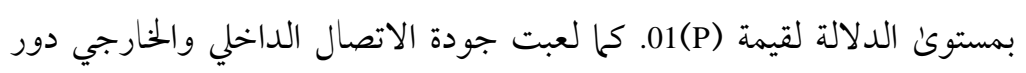
وسيطا بمستوى تأثير (2916. ) ومستوكن دلالة 015. 9- دلالة الدور الوسيط لجودة حياة العمل في مستوى تأثير أبعاد رأس المال النفسي علني

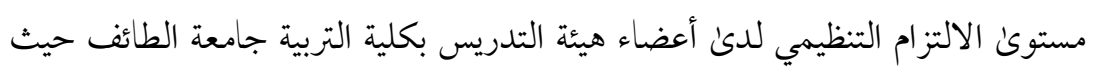

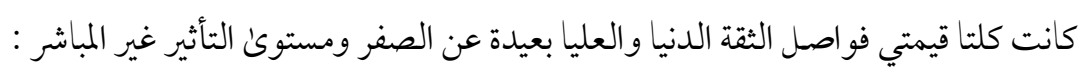

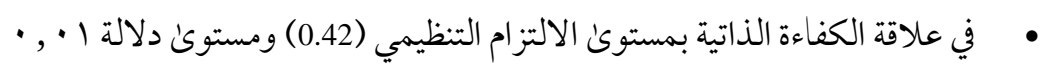


في علاقة التفاؤل بالالتزام التنظيمي (39.)، ومستوئ الدلالة لقيمة (P) (005.) في علاقة مستوى الأمل بمستوئ الالتزام التنظيمي (38.) ومستوى دلالة 02. في علاقة النهوض بمستوى الالتزام التنظيمي بلغ (0.43) مستوئ الدلالة لقيمة (P)

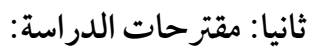

تم تقسيم المقترحات إلى: مقترحات تنفيذية، ودراسات وبحوث مستقبلية مقترحة

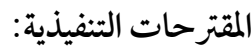

\section{أ- مقترحات لتحسين جودة حياة العمل}

وضع نظام مرن وعادل للمكافآت والتقدير: يشمل هذا النظام المكافآت المادية؛ لأن هذا يعد السبب الرئيس الذي يجعل عضو هيئة التدريس يعمل، ويلتزم تجاه كليته، ويزيد الدافع لديه لاستثلار المزيد من الوقت والطاقة في وظيفته إن توفير، إضافة للمكافئات النفسية بشعور أعضاء هيئة التدريس بالاحترام والتقدير، وأن مصالحهم في قلب الإدارة، وهذا يعد تعويض عن المكافئات المادية حال عدم توفرها. تحسين فرص التنمية المهنية والنمو الوظيفي: من خلال تطوير آليات التدريب وتنويعها، وإعلام أعضاء هيئة التدريس بالفعاليات العلمية محليا وخارجيا، وتشجيعهم علن المشاركة بها سواء من السعوديين، أو غير السعوديين، إضافة إلى التمكين بتعريضهم لمزيد من

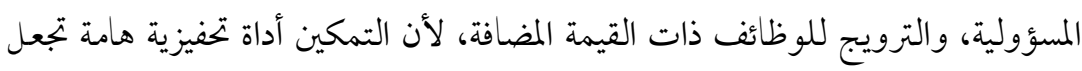
الموظفين مستقلين، وتدفعهم للالتزام برؤية الكلية وأهدافها. تقديم برامج تحت شعار الرعاية الكلية لأعضاء هيئة التدريس من خلالها يتم تقديم الدعم لأعضاء هيئة التدريس اجتماعيا وأسريا لتحسين جودة الحياة الكلية لهم وتقليل الفجوة بين الحياة العملية والحياة العامة. ويمكن أن يتم ذلك من خلال برامج الكترونية، أو تطبيقات يسجل بها عضو هيئة التدريس بياناته، وبينات أسرته واحتياجاتهم التعليمية، والصحية 
و الاجتماعية وغيرها، ويتم من الجهة الأخرىن تسجيل بينات لمتطوعين، أو متعاقدين لتقديم خدمات بجانية لهم متنى توافر ذلك. تعزيز اللجان الاجتماعية بالكلية لتحسين العلاقات بين أعضاء هيئة التدريس، وتحسين مستوى الاتصالات الرسمية وغير الرسمية بينهم. عمل برنامج لدعم الدافعية لدن أعضاء هيئة التدريس، تتضمن التمكين، والتقدير، والاستقلالية، والاستقرار، والولاء، ويتم تحديد أهداف إجرائية لها وعمل خطة تنفيذية ومؤشرات للتقدم في تحقيقها، هذا من أجل تطوير الالتزام التنظيمي. ب- مقترحات خاصة بتعزيز رأس المال النفسي تصميم دليل تطبيقي يسلم لكل عضو هيئة تدريس يستهدف تحسين رأس المال النفسي

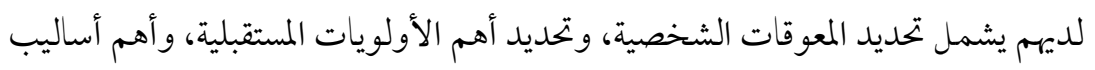
تنمية الذات، لتشخيص واقعه بدقه وتحديد توجهاته المستقبلية، واستراتيجيات متفردة لتنمية مستوئ الأمل، و النهوض و التفاؤل و الكفاءة الذاتية. إصدار الكلية بالتعاون لمجموعة من المقاييس تكون متاحة على موقعها يكون من بينها مكونات رأس المال النفسي لزيادة، وعي أعضاء هيئة التدريس بمستواهم والتطوير بناء علن نتائجه.

توفير مسببات السعادة بالكلية مثل الترفيه (لتحسين مستوئ التفاؤل، والكفاءة الذاتية)، و المشاركة وفرق العمل ودعم عمل اللجان الاجتحاعية (لتنمية مستوئ النهوض من خلال مراقبة النمو الشخصي في وجود الآخرين ومقارنة الذات بفريق العمل) كما أن العمل ضمن الفرق يتيح تنمية مستون الكفاءة الذاتية؛ لأنه يتيح للفرد رفع مستون الإقناع

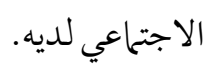


تصميم حجرات للتأمل موجودة ببعض الجامعات (مثل جامعة الملك سعود) تتيح لعضو هيئة التدريس التأمل والاسترخاء، والوقوف علن الخبرات السابقة، ومقارنة وضعه الحلالي ببعض محكات التطوير. الاهتحام بتحسين جودة حياة العمل، وأبعادها السابق ذكرها حيث أثبتت الدراسة وجود علاقة ارتباطية طردية عالية بين مستوى رأس المال النفسي، وأبعاده وجودة حياة العمل. ج- مقترحات خاصة بتدعيم الالتزام التنظيمي: الاهتحام بمكونات تحسين جودة حياة العمل السابق ذكرها، والتي أثبتت الدراسة وجود علاقة ارتباطية طردية عالية بين جودة حياة العمل، وأبعادها ومستوئ الالتز ام التنظيمي. ترقية أهداف الجامعة، والكلية لتتو اكب مع الاتجاهات الدولية، والمحلية التي تلبي طموح أعضاء هيئة التدريس في الرغبة، والتمسك بالعمل المستمر بالكلية، وتطوير الخطط الإجر ائية لتنفيذ هذه الأهداف حتى لا يشعر عضو هيئة التدريس بالفجوة بين الواقع، وما هو معلن، ما ينتج عنه من تقدير لأهداف الكلية. رفع المهارات القيادية والإدارية لرؤساء الأقسام من خلال برامج تدريبية منتظمة لتعزيز دورهم في تنمية الالتزام التنظيمي لدى أعضاء هيئة التدريس التابعين لهم. توفير التجهيزات والتسهيلات، والخدمات (مكاتب مجهزة، أجهزة حاسب آلي شخصية ومكتبية، مواقف سيارات، وغيرها) لعضو هيئة التدريس للمساهمة في رفع مستون

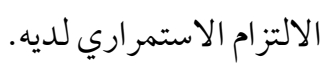

تصميم جدول للمشاركة المجتمعية من قبل أعضاء هيئة التدريس لتعزيز علاقته بالمجتمع، وتعزيز مستوى الالتزام العاطفي، والمعياري لديه من انتسابه لمؤسسة كبيرة لها سمعة عالية

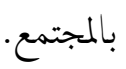


إتاحة الفرصة لمشاركة أعضاء هيئة التدريس في وضع أهداف الكلية، والمشاركة في صنع القرارات الإدارية، من خلال تفويض مرن للسلطة والبعد عن البيروقراطية التي تقصي

$$
\text { البحوث المقترحة: }
$$

دور الدافعية الداخلية، والمحفزات الخارجية في التنبؤ بمستوئ الأداء لدى أعضاء هيئة

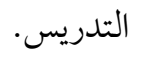

العوامل النفسية المؤثرة في مستون الالتزام التنظيمي، والرضا الوظيفي لدى أعضاء هيئة

$$
\text { التدريس بالجامعات المصرية. }
$$

دور مهار ات الاتصال لدئ القيادات في التنبؤ بمستوى التماثل مع الهوية التنظيمية.

• استراتيجية مقترحة لتحسين جودة حياة العمل بالجامعات السعودية.

• أثر بعض المتغيرات الديموغر افية في مستوكئ الكفاءة الذاتية، والنهوض بالكليات العلمية.

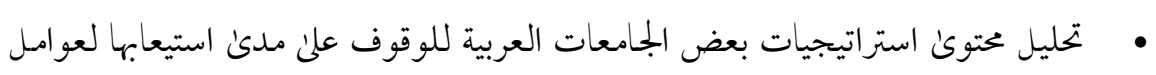

تنمية الالتزام التنظيمي، ورأس المال النفسي لدئ منسوبيها. 


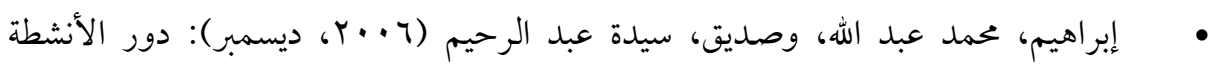

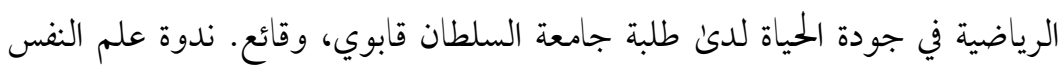
وجودة الحياة، جامعة السلطان قابوس: مسقط . لمان.

أبو حلاوة، محمد السعيد(ع) (Y).علم النفس الإيجابي: مـاهيته ومنطلقاته النظرية وآفاقه

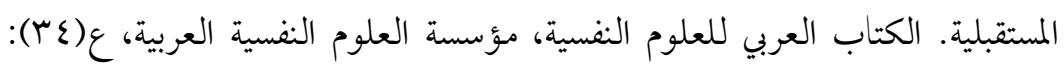

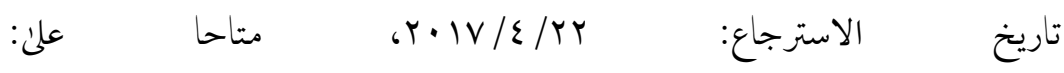
http://arabpsynet.com/apneBooks/eB34/eB34MSACont\&Pref. pdf أبوليفة، سناء مصطفي محمد (2016) دور رأس المال النفسي الإيجابي في العلاقة بين جودة

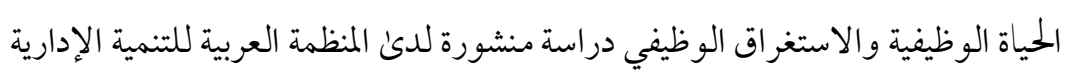

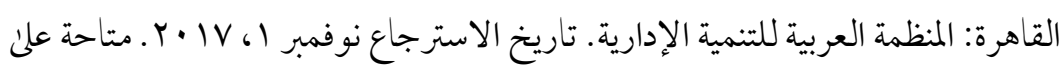
https://www.arado.org/PublicationDetails.aspx?PubID=3787:

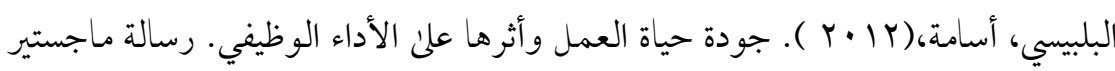

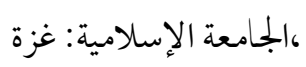
حسين، محمد عبد الهادي (r...r). قياس وتقييم قدرات الذكاءات المتعددة، القاهرة: دار الفكر العربي.

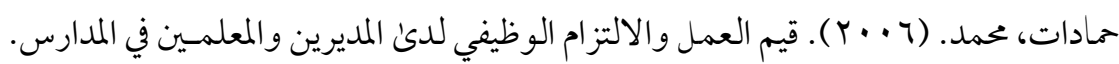
عان: دار ومكتبة الحامد. خضير، نعمة عباس (1996). الالتزام التنظيمي وفاعلية المنظمة دراسة مقارنة بين الكليات

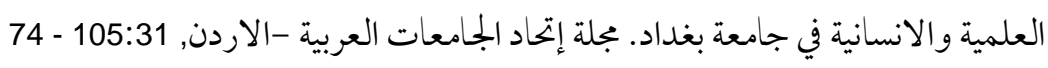
الدخيل الله، دخيل الله (1990).مقدمات الالتزام لمنظمة أكاديمية. مجلة العلوم التربوية

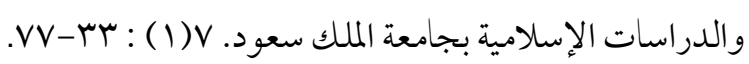




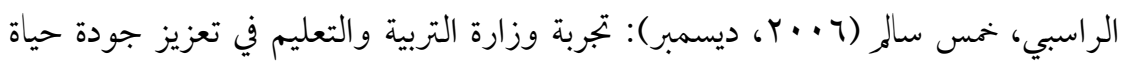
المتعلمين بمدارس السلطنة، ندوة علم النفس وجودة الحياة، جامعة السلطان قابوس: مسقط

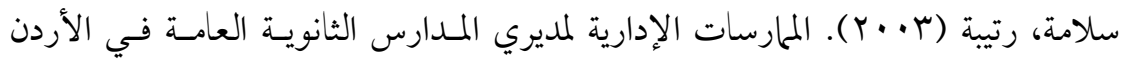
وعلاقتها بالرضا الوظيفي والولاء التنظيمي للمعلمين.رسالة دكتوراه غير منشـورة . جامعة عحان العربية للدراسات العليا: الأردن.

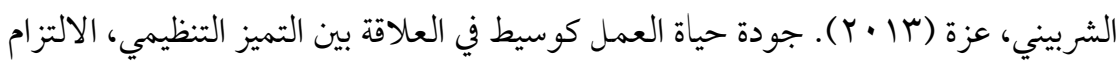
التنظيمي بالتطبيق علن القطاع المصرفي في محافظة الدقهلية (بنوك القطاع العام التجارية، والبنوك المتخصصة، والبنوك الاستثارية) بجلة الدراسات والبحوث التجارية ببنها: 179-236

المغربي، عبد الفتاح (ع · · r). جودة حياة العمل و أثرها في تنمية الاستغراق الوظيفي: دراسة

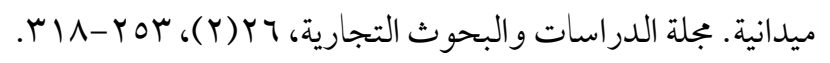

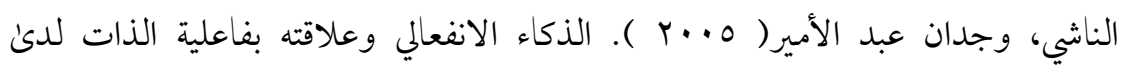
المدرسين. رسالة دكتوراه ( غير منشوره ) كلية الآداب، جامعة المستصرية: بغداد. اليوسف، جواهر بنت خالد (سبع () المشكـلات التي تواجه أعضـاء هيئة التدريس بجامسعه سلمان بن عبد العزيز. رسالة ماجستير. قسم الإدارة والتخطيط التربوي، كلية

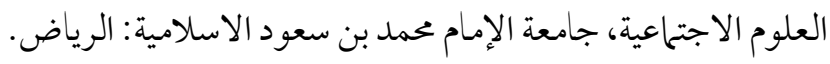




\section{References}

- Abu Halawa, Mohamed Al-Said (2014). Positive Psychology: What it is, its theoretical points of view and its future prospects. Arab Book of Psychological Sciences, Arab Psychological Institute, 34: Retrieved on: 22/4/2017, available at: http://arabpsynet.com/apneBooks/eB34/eB34MSACont\&Pref.pdf

- Abulifa, Sana Mustafa Mohammed (2016). The Role of Positive Psychological Capital in the Relationship between the Quality of Career Life and job Identification. Published by the Arab Organization for Administrative Development Cairo: The Arab Organization for Administrative Development. Retrieved on :November 1, 2017. Available at: https://www.arado.org/PublicationDetails.aspx?PubID=3787

- Ahmadi, F., Salavati, A., \& Rajabzadeh, E. (2012). Survey Relationship Between Quality of Work Life and Organizational Commitment in Public Organization in Kurdistan Province. Interdisciplinary Journal of Contemporary Research in Business, 4 (1), 235-247.

- Al Nashi, Wajdan Abdul Amir (2005). Emotional intelligence and its relation to the selfefficacy of teachers. PhD thesis (unpublished) Faculty of Arts, University of Mustansiriya: Baghdad.

- Allen, N \& Meyer, J (1990). The Measurement and Antecedents of Affective, Continuance and Normative Commitment to the Organization. Journal of Occupational Psychology, 63, 1-18.

- Almaghraby, Abdel Fattah (2004). Quality of work life and its impact on the development of employment: a field study. Journal of Studies and Business Research, 26 (2), 253-318.

- $\quad$ Almarshad, S. (2015). Quality of Work Life and Organizational Commitment in Saudi Arabia: The Role of Job Involvement and Sense Of Efficacy. European Journal of Business and Social Sciences, 4(2):141-158.

- $\quad$ Alyousef, Jawaher(1433H) . Problems with faculty members at Salman bin Abdul Aziz University. Master Thesis. Department of Management and Educational Planning, Faculty of Social Sciences, Imam Muhammad bin Saud Islamic University: Riyadh.

- Aminikhah, H., Khaneghah, T. M., \& Naghdian, M. (2016). The relationship of psychological capital and job satisfaction with organizational 


\section{/ محمود سيد علي أبو سيف

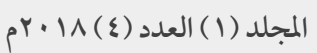

commitment. International Journal of Information, Business and Management, 8(1), 153-17 .

- $\quad$ Asgari, M. H., \& Dadashi, M. A. (2011). Determining the Relationship Between Quality of Work Life ( QWL ) and Organizational Commitment of Melli Bank Staff in West Domain of Mazandaran in. Management, 5(8), 682-687.

- Bandura, A. (1994). Self-efficacy. In V. S. Ramachaudran (Ed.), Encyclopedia of human behavior (Vol. 4, pp. 71-81). New York: Academic Press. (Reprinted in H. Friedman [Ed.], Encyclopedia of mental health. San Diego: Academic Press, 1998)

- Baron, A. R. \& Greenberg, J. (2003). Organizational Behaviour in Organization. Understanding and managing the human side of work. Canada: Prentice Hall.

- $\quad$ Baron, R., \& Kenny, D. (1986). The moderator-mediator variable distinction in social psychological research: Conceptual, strategic, and statistical considerations. Journal of Personality and Social Psychology, 51, 1173-1182.

- $\quad$ Bharathi, P.Subburethina; Umaselvi., M. and Kumar N.(2011) Senthil Quality of work life: Perception of college teachers. A study submitted to Munich Personal RePEc Archive. Retrieved on 1/11/2017. Available at: https://mpra.ub.unimuenchen.de/27868/1/Quality_of_work_lifeperception_of_college_teachers.pdf

- $\quad$ Bilbisi, Osama, (2012). Quality of work life and its impact on job performance. Master Thesis, Islamic University: Gaza

- Bitmiş, M. G., \& Ergeneli, A. (2015). How Psychological Capital Influences Burnout: The Mediating Role of Job Insecurity. Procedia - Social and Behavioral Sciences, 207, 363-368.

- Business dictionary online a (undated). Definition of organizational commitment. Retrieved November 16 2017. Retrieved from: http://www.businessdictionary.com/definition/organizationalcommitment.html

- $\quad$ Business dictionary online b (undated). Definition of Quality of work life. Retrieved November 16 2017. Retrieved from: http://www.businessdictionary.com/definition/quality-ofworklife.html 
- Butler, Adam ( undated). Mediator variables. University of Northern Iowa site. Retrieved on 22Nov, 2017. Retrieved form: https://sites.uni.edu/butlera/courses/org/modmed/moderator_mediat or.htm

- Charney, D.S. (2004). Psychobiological mechanisms of resilience and vulnerability; Implications for successful adaption to extreme stress. American Journal of Psychiatry, 161, 195-216

- Chen, G., Whiteman, J. A., Gully, S. M., \& Kilcullen, R. N. (2000). Examination of relationships among traitlike individual differences, state-like individual differences, and learning performance. Journal of Applied Psychology, 85: 835847.

- Dakhilullah, Dakhilullah (1995). Commitment to an academic organization. Journal of Educational Sciences and Islamic Studies, King Saud University. 7 (1): 33-77.

- $\quad$ Dargahi, H., and Yazdi, M.K. (2007). "Quality of Work life in Tehran University of Medical Sciences Hospitals' Clinical Laboratories Employees ". Pakistan Journal of Medical Sciences, 23, 4 630-633.

- $\quad$ Easton, Simon\& Van Laar, Darren (2013). QoWL (Quality of Working Life)—What, How, and Why? Psychology Research, 3(10), 596-605.

- $\quad$ Erkuş, A., Fındıklı, M. (2013), Psychological Capital and its Impact on Job Satisfaction, Job Performance and Job Turnover Intentions, Istanbul University Journal of the School of Business, 42(2), 302-318.

- Etebarian, A., Tavakoli, S., \& Abzari, M. (2012). The relationship between psychological capital and organizational commitment. African Journal of Business Management, 6(14), 5057-5060.

- Etebarian, A., Tavakoli, S., \& Abzari, M. (2012). The relationship between psychological capital and organizational commitment. African Journal of Business Management, 6(14), 5057-5060. https://doi.org/10.5897/AJBM11.2844

- $\quad$ Farid, H., Izadi, Z., Ismail, I. A., \& Alipour, F. (2014). Relationship between quality of work life and organizational commitment among lecturers in a Malaysian public research university. The Social Science Journal. https://doi.org/10.1016/j.soscij.2014.09.003 
- $\quad$ Flach, F. F. (1989). Resilience: Discovering new strength at times of stress. New York: Ballantine Books.

- $\quad$ Gokhan, B., Azize, E. (2014), The Role of Psychological Capital and Trust in Individual Performance and Job Satisfaction Relationship: A Test of Multiple Mediation Model. Procedia Social and Behavioral Sciences, 99(1), 173-179.

- Hammadat, Mohamed. (2006). Values of work and commitment of school principals and teachers. Amman: Al Hamed House and Library.

- Han, K.-S., \& Chung, K.-H. (2015). Study on the positive psychological capital, organizational commitment and job stress. International Journal of Applied Engineering Research, 10(18), 39366-39371. Retrieved on October 5/2017. Available at:http://www.scopus.com/inward/record.url?eid=2-s2.084944520319\&partnerID=40\&md5=40c3ff2 b5e8ea01fa630d239382 20479

- Hayes, A. F. (2013). Introduction to mediation, moderation, and conditional process analysis: A regression-based approach. New York: Guilford Press

- $\quad$ Hong, K. S., Kok, W. T., \& Suraini, B. (2010). Relationships between work life quality of teachers with work commitment, stress and satisfaction: a study in kuching, sarawak, malaysia. Jurnal Teknologi, 52(Mei), 1-15.

- Hussain, T., \& Saleem, S. (2014). Do employees' job satisfaction, involvement and commitment mediate relationship between quality of work life and employees' retention? Middle - East Journal of Scientific Research, 19(1), 115-122.

- Hussein, Mohamed Abdel Hadi (2003). Measuring and Evaluating the Capacities of Multiple Intelligences, Cairo: Arab Thought House.

- $\quad$ Ibrahim, Mohammed Abdulla, and Sadiq, Sayyidah Abdul Rahim (2006, December): The role of sports activities in the quality of life among students of Sultan Qabawi University. Seminar on Psychology and Quality of Life, Sultan Qaboos University: Muscat.

- Jung, H., Yoon, H. (2015), The Impact of Employees' Positive Psychological Capital on Job Satisfaction and Organizational Citizenship Behaviors in the Hotel, International Journal of Contemporary Hospitality Management, 27(6),1135-1156. 
- Kanten, P. (2014). Effect of Quality of Work Life (Qwl) on Proactive and Pro-social Organizational Behaviors: A Research on Health Sector Employees. The Journal of Faculty of Economics, 19, 1, 251-274.

- $\quad$ Kee, L. B., Ahmad, R. bin, \& Abdullah, S. M. (2016). Relationship between Financial Compensation and Organizational Commitment among Malaysian Bank Workers. Asian Business Research, 1(1), 75.

- $\quad$ Keye, Michelle D\& Pidgeon, Aileen M. (2013). An Investigation of the Relationship between Resilience, Mindfulness, and Academic Self-Efficacy. Open Journal of Social Sciences 1(6), 1-4. Retrieved on 11/11/2017. Published Online on:(http://www.scirp.org/journal/jss )http://dx.doi.org/10.4236/jss.2013.16001

- $\quad$ Khorsandi, M., Jahani, F., Rafie, M., \& Farazi, A. (2010). Health -Related quality of life in staff and hospital personnel of arak university of Medical sciences. Journal of Arak Medical University,13(1), 40-48.

- $\quad$ Khudair, Nima Abbas (1996). Organizational Commitment and the Effectiveness of the Organization : A Comparative Study between the Scientific and Human Faculties at the University of Baghdad. Journal of the Union of Arab Universities - Jordan 31, $74-105$

- Legal, Jean-Baptiste and Thierry Meyer (2009). Goal Priming and Self-Efficacy: Independent Contributions to Motor Performance. Perceptual and Motor Skills, 108 (2), 383-391.

- $\quad$ Lewis, D., Brazil, K., Kruger, P., Lohfeld, L., and Tjam, E. (2001). Extrinsic and intrinsic determinants of work life. Leadership in Health Services, 14 (2), ix - xv.

- Luthans F, Youssef CM. (2007). Emerging positive organizational behavior. Journal of Management, 33, 321-349.

- Luthans, F. (2002). Positive organizational behavior: Developing and managing psychological strengths. Academy of Management Executive, 16(1): 57-72.

- $\quad$ Luthans, F., Norman, S. M., Avolio, B. J., \& Avey, J. B. (2008). The mediating role of psychological capital in the supportive organizational climate-employee performance relationship. Journal of Organizational Behavior, 29, 2319-2238.

- $\quad$ Luthans, F., Vogelgesang, G. R., \& Lester, P. B. (2006). Developing the psychological capital of resiliency. Human Resource Development Review, 5(1): 25-44. 1 
- Luthans, Fred, Avolio, Bruce J., Fred O. Walumbwa, And Weixing Li (2005). The Psychological Capital Of Chinese Workers: Exploring The Relationship With Performance. Management And Organization Review, 1 (2), 249-271.

- Luthans, Fred, Avolio, Bruve J., James B. Avey And Steven M. Norman (2007), Positive Psychological Capital: Measurement And Relationship With Performance And Satisfaction. Personnel Psychology, 60, 541-572.

- $\quad$ Lyubomirsky, Sonja (2008). The How of Happiness: A New Approach to Getting the Life You Want. New York: Penguin Press.

- $\quad$ Meyer, J. P., Allen, N. J., \& Smith, C. A. (1993). Commitment to organizations and occupations: Extension and test of a three-component conceptualization. Journal of Applied Psychology, 78(4), 538-551.

- $\quad$ Miller, K. (2003).Values, attitudes and job satisfaction. In Robbins, S.P., Odendaal A. \& Roodt, G. (eds), Organisational Behaviour: Global and Southern African Perspectives. Cape Town: Pearson Education South Africa.

- Mohammadi, S.; Vaisi, K. \& Moradi, J. (2016). Relationship between psychological capital and organizational commitment with job satisfaction of physical educators in Kurdistan province. International journal of humanities and cultural studies, April issue, 65-74.

- $\quad$ Mortazavi, S., Yazdi, S. V. S., \& Amini, A. (2012). The role of the psychological capital on quality of work life and organization performance. Interdisciplinary Journal of Contemporary Research in Business, 4(2), 206-217.

- Mullins, J. L. (1996). Management and Organizational Behavior. London: Pitman Publishing.

- $\quad$ Nadler, David and Lawler, Edward. (1983). quality of work life: perspectives and directions. Organizational Dynamics, Vol. 11, $22-36$.

- $\quad$ Nanjundeswaraswamy, T.S., Swamy, D. R. (2013). Review of Literature on Quality of Work Life. International Journal for Quality Research, 7( 2), 201-214.

- $\quad$ Nguyen Tho\& Nguyen, Trang. (2012). Psychological Capital, Quality of Work Life, and Quality of Life of Marketers: Evidence from Vietnam. Journal of Macro marketing 32(1):87-95. 
- $\quad$ Ojedokun, O., Idemudia, E. S., \& Desouza, M. (2015). Perceived external prestige as a mediator between quality of work life and organizational commitment of public sector employees in Ghana. SA Journal of Industrial Psychology, 41(1), 1-10.

- $\quad$ Pani, Debasis (2015). A Study on Quality of Work Life with Special Reference to Private Engineering College Teachers in the District of Rayagada. Journal of Management and Science ,5(3):81-90.

- $\quad$ Parker, S. (1998). Enhancing role-breath self efficacy: The roles of job enrichment and other organizational interventions. Journal of Applied Psychology, 83, 835-852. http://dx.doi.org/10.1037/0021-9010.83.6.835

- $\quad$ Preacher, K.J., \& Hayes, A.F. (2004). SPSS and SAS procedures for estimating indirect effects in simple mediation models. Behavior Research Methods, Instruments, \& Computers, 36, 717-731.

- Randall, D. M. (1987). Commitment and the organization: The organization man revisited. Academy of Management Review, 12(3), 460-460.

- Rasby, Khamis Salem (2006, December): The experience of the Ministry of Education in enhancing the quality of life of learners in the Sultanate's schools. Seminar on psychology and quality of life, Sultan Qaboos University: Muscat.

- Roos, J.; Roos, G., Dragonetti, N., \& Edvinsson, L. (1997). Intellectual Capital: Navigating in the New Business Landscape. New York: New York University Press.

- $\quad$ Roscoe, J. T. (1975). Fundamental research statistics for the behavioral sciences (2nd ed.) .New York: Holt, Rinehart and Winston.

- $\quad$ Salameh, Ratibah (2003). The administrative practices of the general secondary school principals in Jordan and their relation to the job satisfaction and the organizational loyalty of the teachers. Amman Arab University for Graduate Studies: Jordan.

- $\quad$ Scheier, M.F., \& Carver, C.S. (1985). Optimism, coping, and health: Assessment and implications of generalized outcome expectancies. Health Psychology, 4, 219-247.

- $\quad$ Seligman, M.( 1998). Learned optimism. New York: Pocket. Shifren, K., \& Hooker, K. 1995. Stability and change in optimism: A study among spouse caregivers. Experimental Aging Research, 21: 59-76.

- $\quad$ Seligman, M., \& Csikszentmihalyi, M.(2000). Positive psychology: An introduction. American Psychologist, 55, 5-14. 
- Shabn, ambidarian, Parivash, jafari\& Nader, gholighourchian(2016). The Relationship between Quality Of Lifeand Psychological Capital in Faculty Members of Islamic Azad University in Iran. IOSR Journal of Business and Management (IOSR-JBM), 17 (7), 116-120.

- Shahnawaz, M., \& Hassan, M. (2009). Psychological Capital as Predictors of Organizational Commitment and Organizational Citizenship Behaviour. Journal of the Indian Academy of Applied Psychology, 35(October), 78-84.

- Sharifi, N., \& Shahtalebi, B. (2014). The Relationship between Dimensions of Psychological Capital with Organizational Commitment Studied: Staffs of General Directorate of Education of Isfahan. Kuwait Chapter of Arabian Journal of Business and Management Review, 3(11), 23-31.

- $\quad$ Sherbini, Azza (2013). The quality of working life as an intermediary in the relationship between organizational excellence and organizational commitment in applying to the banking sector in Dakahlia governorate (commercial public sector banks, specialized banks and investment banks). Journal of Business Studies and Research, Benha: 179-236

- $\quad$ Snyder, C, Shorey, H.S., Cheavens, J., Pulvers, K.M., Adams, V.H., \& Wiklund, C. (2002). Hope and Academic Success in College. Journal of Educational Psychology, 94 (4), 820-826.

- $\quad$ Snyder, C. R., Harris, Cheri, John R. Anderson, Sharon A. Holleran, Lori M. Irving, Sandra T. Sigmon, Lauren Yoshinobu, June Gibb, Charyle Langelle And Pat Harney (1991). The Will and the Ways: Development and Validation of an IndividualDifferences Measure of Hope. Journal of Personality and Social Psychology, 60 (4), 570-585.

- $\quad$ Snyder, C.( 2002). Hope theory: Rainbows in the mind. Psychological Inquiry, 13: 249276.

- $\quad$ Snyder, C., \& Lopez, S. ( 2002). Handbook of positive psychology. Oxford, UK: Oxford University Press.

- $\quad$ Snyder, C., Sympson, S., Ybasco, F., Borders, T., Babyak, M., \& Higgins, R. (1996). Development and validation of the state hope scale. Journal of Personality and Social Psychology, 70, 321-335. 
- $\quad$ Stajkovic, A., \& Luthans, F. (1998). Self-efficacy and work-related performance: A meta-analysis. Psychological Bulletin, 124: 240-261.

- Tams, Svenja (2008). Constructing self- efficacy at work: a person- centered perspective. Personnel Review, 37 (2), 165-183

- Wagnild, G.M., \& Young, H.M. (1993). Development and psychometric evaluation of the resiliency scale. Journal of Nursing Management, 1(2), 165-178.

- Walton, R. (1973). Quality of Working Life: What Is It? Sloan Management Review 15(1): 11-21.

- Wright, P. M., \& Kehoe, R. R. (2007). Human resource practices and organizational commitment: A deeper examination. Asia Pacific Journal of Human Resources, 46(1), 7-22.

- $\quad$ Youssef, Carolyn M. and Luthans, Fred (2007). Positive Organizational Behavior in the Workplace: The Impact of Hope, Optimism, and Resiliency. Journal of Management, 33 (5), 774-800.

- Zhong, L. (2007). Effects of psychological capital on employees' job performance, organizational commitment, and organizational citizenship behavior. [Effects of psychological capital on employees' job performance, organizational commitment, and organizational citizenship. Acta Psychologica Sinica, 39, 328-334. 

Dr. Abosaif, Mahmoud Sayed Ali

Volume (1) No. (4) 2018

http://dx.doi.org/10.29009/ijres.1.4.4 